
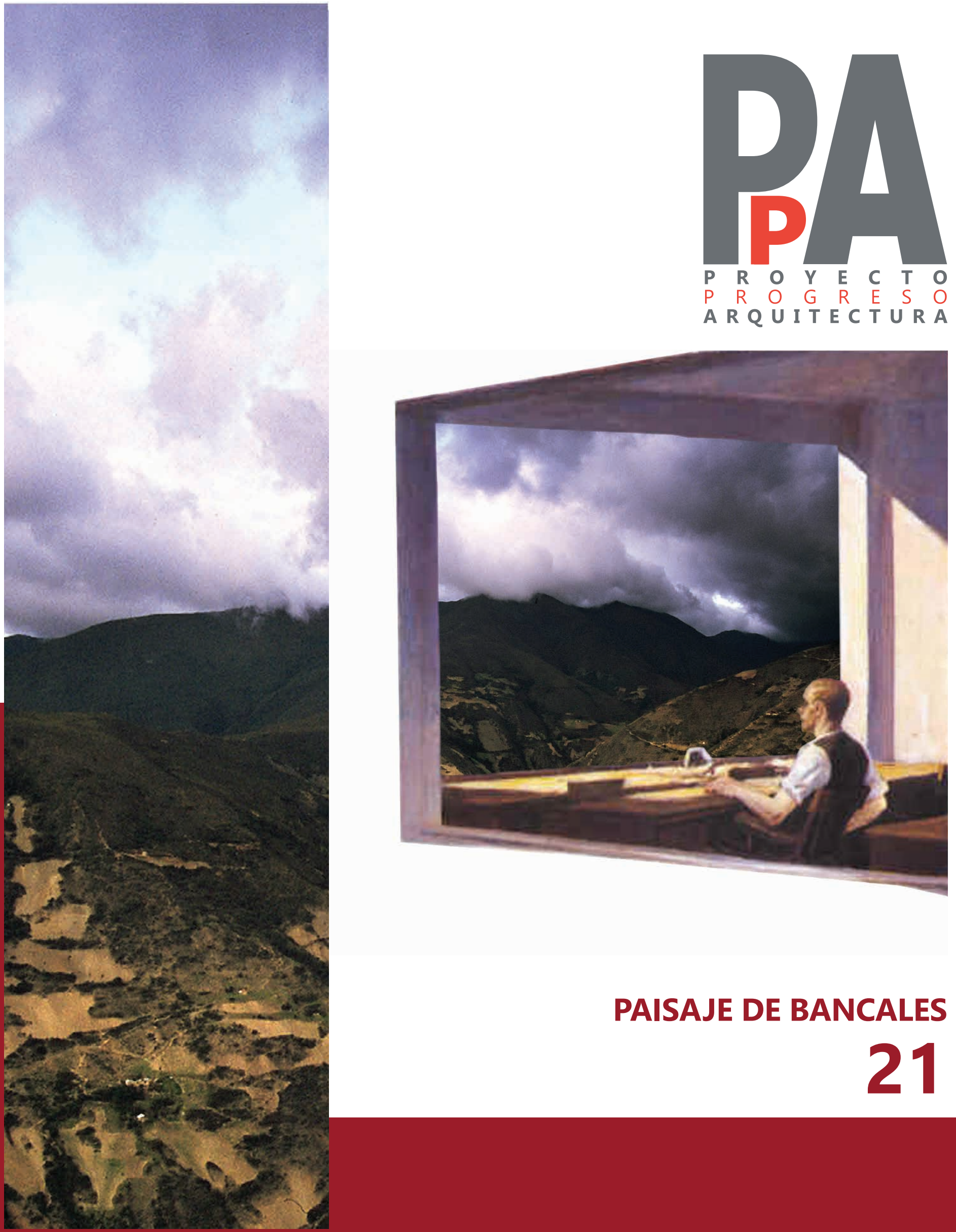

PAISAJE DE BANCALES

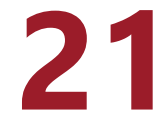




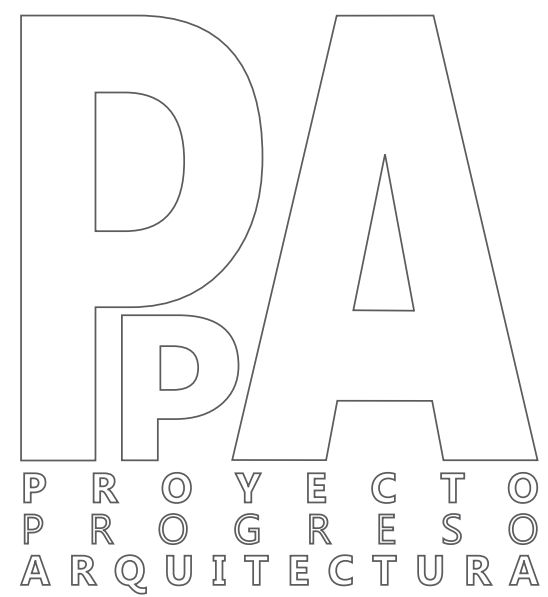

\section{PAISAJE DE BANCALES \\ 21}
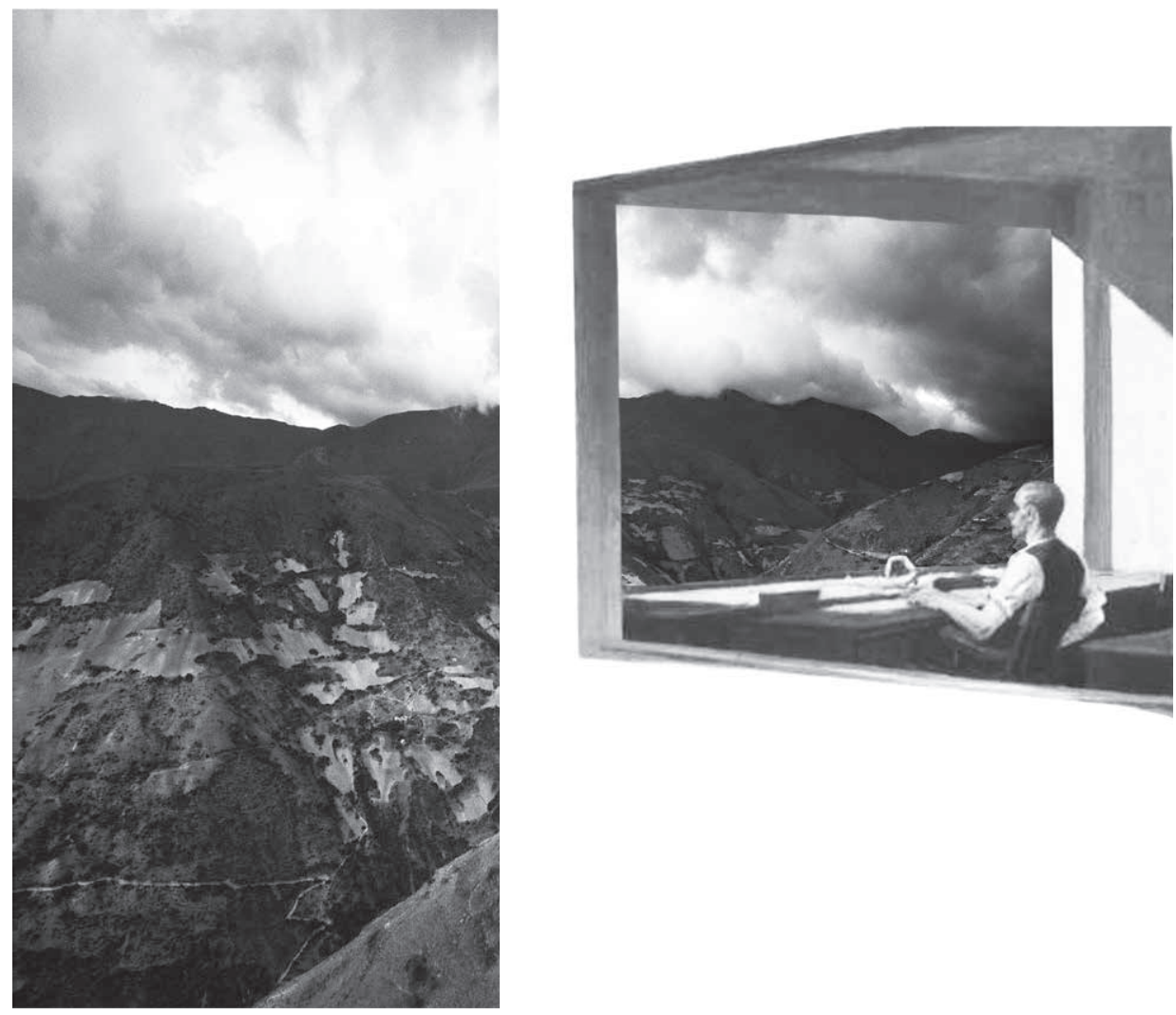


\section{REVISTA PROYECTO PROGRESO ARQUITECTURA}

N22]

\section{paisaje de bancales}
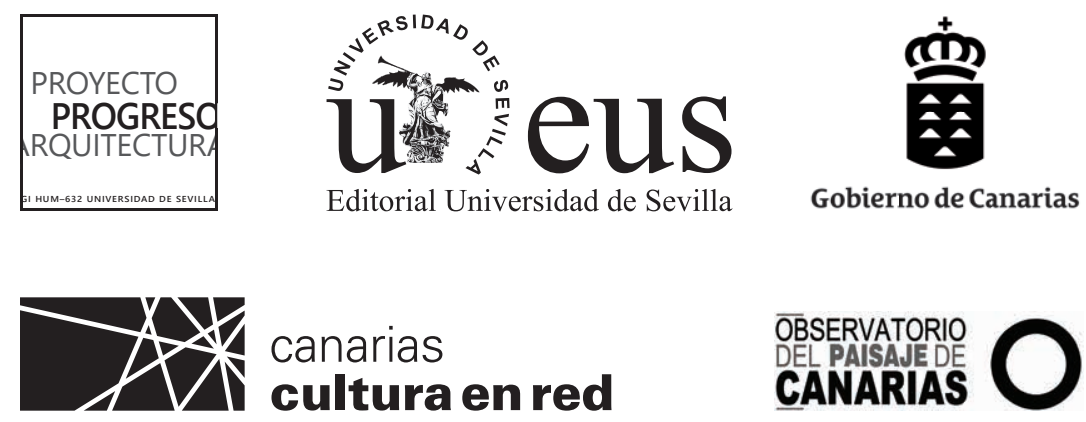
PROYECTO, PROGRESO, ARQUITECTURA. N21, NOVIEMBRE 2019 (AÑO X)

\section{paisaje de bancales}

\section{DIRECCIÓN}

Dr. Amadeo Ramos Carranza. Escuela Técnica Superior de Arquitectura. Universidad de Sevilla. España

\section{SECRETARÍA}

Dra. Rosa María Añón Abajas. Escuela Técnica Superior de Arquitectura. Universidad de Sevilla. España

\section{EQUIPO EDITORIAL}

Edición:

Dr. Amadeo Ramos Carranza. Escuela Técnica Superior de Arquitectura. Universidad de Sevilla. España.

Dra. Rosa María Añón Abajas. Escuela Técnica Superior de Arquitectura. Universidad de Sevilla. España.

Dr. Francisco Javier Montero Fernández. Escuela Técnica Superior de Arquitectura. Universidad de Sevilla. España.

Dr. Alfonso del Pozo Barajas. Escuela Técnica Superior de Arquitectura. Universidad de Sevilla. España.

Dra. Esther Mayoral Campa. Escuela Técnica Superior de Arquitectura. Universidad de Sevilla. España.

Dr. Miguel Ángel de la Cova Morillo-Velarde. Escuela Técnica Superior de Arquitectura. Universidad de Sevilla. España. Dr. Germán López Mena. Escuela Técnica Superior de Arquitectura. Universidad de Sevilla. España.

Juan José López de la Cruz. Escuela Técnica Superior de

Arquitectura. Universidad de Sevilla. España.

Guillermo Pavón Torrejón. Escuela Técnica Superior de Arquitectura. Universidad de Sevilla. España.

Asesores externos a la edición:

Dr. Alberto Altés Arlandis. Post-Doctoral Research Fellow. Architecture Theory Chair . Department of Architecture. TUDelft. Holanda.

Dr. José Altés Bustelo. Escuela Técnica Superior de Arquitectura. Universidad de Valladolid. España.

Dr. José de Coca Leicher. Escuela de Arquitectura y Geodesia. Universidad de Alcalá de Henares. España.

Dr. Jaume J. Ferrer Fores. Escola Tècnica Superior d'Arquitectura de Barcelona. Universitat Politècnica de Catalunya. España.

Dra. Marta Sequeira. CIAUD, Faculdade de Arquitectura da

Universidade de Lisboa, Portugal.

Dr. Carlos Arturo Bell Lemus. Facultad de Arquitectura. Universidad del Atlántico. Colombia.

Carmen Peña de Urquía, architect en RSH-P. Londres. Reino Unido.

SECRETARÍA TÉCNICA

Gloria Rivero Lamela, arquitecto.Personal Investigador en Formación. Universidad de Sevilla. España.

MAQUETA DE LA PORTADA

Miguel Ángel de la Cova Morillo-Velarde

DISEÑO GRÁFICO DE LA MAQUETACIÓN

Maripi Rodríguez

PORTADA:

Del cartel del seminario y de la portada del libro Arquitectura y construcción: el paisaje como argumento(2009). Dir: Ramos-

Carranza, Amadeo; Añón-Abajas, Rosa María

Diseño del cartel: Valentín Trillo Martínez (2007)

ISSN (ed. impresa): 2171-6897

ISSN-e (ed. electrónica): 2173-1616

DOI: http://dx.doi.org/10.12795/ppa

DEPÓSITO LEGAL: SE-2773-2010

PERIOCIDAD DE LA REVISTA: MAYO Y NOVIEMBRE

IMPRIME: PODIPRINT

INICIATIVA DEL GRUPO DE INVESTIGACION HUM-632

"PROYECTO, PROGRESO, ARQUITECTURA"

http://www.proyectoprogresoarquitectura.com
COORDINADOR DE LOS CONTENIDOS CIENTÍFICOS DEL NÚMERO

Dra. Juan Manuel Palerm Salzar. Escuela Técnica Superior de Arquitectura. Universidad de Las Palmas. España.

COMITÉ CIÉNTIFICO

Dr. Gonzalo Díaz Recaséns. Catedrático Proyectos Arquitectónicos. Escuela Técnica Superior de Arquitectura. Universidad de Sevilla. España.

Dr. José Manuel López Peláez. Catedrático Proyectos Arquitectónicos.

Escuela Técnica Superior de Arquitectura. Universidad Politécnica de Madrid. España.

Dr. Víctor Pérez Escolano. Catedrático Historia, Teoría y Composición Arquitectónicas. Escuela Técnica Superior de Arquitectura. Universidad de Sevilla. España.

Dr. Jorge Torres Cueco. Catedrático Proyectos Arquitectónicos. Escuela Técnica Superior de Arquitectura. Universitat Politècnica de València. España. Dr. Armando Dal'Fabbro. Professore Associato. Dipartimento di progettazione architettonica, Facoltà di Architettura, Universitat Instituto Universitario di Architettura di Venezia. Italia.

Dra. Anne-Marie Chatelêt. Professeur Titulaire. Histoire et Cultures Architecturales. École Nationale Supérieure d'Architecture de Stragbourg. Francia.

Dr. ir. Frank van der Hoeven, TU DELFT. Architecture and the Built Environment, Netherlands

EDITA

Editorial Universidad de Sevilla. Sevilla

DIRECCIÓN CORRESPONDENCIA CIENTÍFICA

E.T.S. de Arquitectura. Avda Reina Mercedes, nº 2 41012-Sevilla.

Amadeo Ramos Carranza, Dpto. Proyectos Arquitectónicos.

e-mail: revistappa.direccion@gmail.com

EDICIÓN ON-LINE

Portal informático https://revistascientificas.us.es/index.php/ppa Portalinformático G.I.HUM-632 http://www.proyectoprogresoarquitectura.com Portal informático Editorial Universidad de Sevilla http://www.editorial.us.es/

(C) EDITORIAL UNIVERSIDAD DE SEVILLA, 2019

Calle Porvenir, 27. 41013 SEVILLA. Tfs. 954487447 / 954487451

Fax954487443. [eus4@us.es] [http://www.editorial.us.es]

(c) TEXTOS: SUS AUTORES, 2019.

(c) IMÁGENES: SUS AUTORES Y/O INSTITUCIONES, 2019.

SUSCRIPCIONES, ADQUISICIONES Y CANJE revista PROYECTO, PROGRESO, ARQUITECTURA

Editorial Universidad de Sevilla.

Calle Porvenir, 27. 41013 SEVILLA. Tfs. 954487447 / 954487451

Fax 954487443

Reservados todos los derechos. Ni la totalidad ni parte de esta revista puede reproducirse o transmitirse por ningún procedimiento electrónico o mecánico, incluyendo fotocopia, grabación magnética o cualquier almacenamiento de información y sistema de recuperación, sin permiso escrito de la Editorial Universidad de Sevilla.

Las opiniones y los criterios vertidos por los autores en los artículos firmados son responsabilidad exclusiva de los mismos.

COLABORA DEPARTAMENTO DE PROYECTOS ARQUITECTÓNICOS Escuela Técnica Superior de Arquitectura. Universidad de Sevilla. http://www.departamento.us.es/dpaetsas 


\section{revista PROYECTO, PROGRESO, ARQUITECTURA}

Nuestra revista, fundada en el año 2010, es una iniciativa del Grupo de Investigación de la Universidad de Sevilla HUM-632 "proyecto, progreso, arquitectura" y tiene por objetivo compartir y debatir sobre investigación en arquitectura. Es una publicación científica con periodicidad semestral, en formato papel y digital, que publica trabajos originales que no hayan sido publicados anteriormente en otras revistas. Queda establecido el sistema de arbitraje para la selección de artículos a publicar mediante dos revisores externos -sistema doble ciego- siguiendo los protocolos habituales para publicaciones científicas seriadas. Los títulos, resúmenes ,palabras clave y texto completo de los artículos se publican también en lengua inglesa.

"proyecto, progreso, arquitectura" presenta una estructura clara, sencilla y flexible. Trata todos los temas relacionados con la teoría y la práctica del proyecto arquitectónico. Las distintas "temáticas abiertas" que componen nuestra línea editorial, son las fuentes para la conjunción de investigaciones diversas.

La revista va dirigida a arquitectos, estudiantes, investigadores y profesionales relacionados con el proyecto y la realización de la obra de arquitectura.

Our journal, "proyecto, progreso, arquitectura", founded in 2010, is an initiative of the Research Group HUM-632 of the University of Seville and its objective is the sharing and debating of research within architecture. This six-monthly scientific publication, in paper and digital format, publishes original works that have not been previously published in other journals. The article selection process consists of a double blind system involving two external reviewers, following the usual protocols for serial scientific publications. The titles, summaries, key words and full text of articles are also published in English.

"proyecto, progreso, arquitectura" presents a clear, easy and flexible structure. It deals with all the subjects relating to the theory and the practise of the architectural project. The different "open themes" that compose our editorial line are sources for the conjunction of diverse investigations.

The journal is directed toward architects, students, researchers and professionals related to the planning and the accomplishment of the architectural work.

\section{SISTEMA DE ARBITRAJE}

EVALUACIÓN EXTERNA POR PARES Y ANÓNIMA

El Consejo Editorial de la revista, una vez comprobado que el artículo cumple con las normas relativas a estilo y contenido indicadas en las directrices para los autores, remitirá el artículo a dos expertos revisores anónimos dentro del campo específico de investigación y crítica de arquitectura, según el modelo doble ciego.

Basándose en las recomendaciones de los revisores, el director de la revista comunicará a los autores el resultado motivado de la evaluación por correo electrónico, en la dirección que éstos hayan utilizado para enviar el artículo. El director comunicará al autor principal el resultado de la revisión (publicación sin cambios; publicación con correcciones menores; publicación con correcciones importantes; no aconsejable para su publicación), así como las observaciones y comentarios de los revisores.

Si el manuscrito ha sido aceptado con modificaciones, los autores deberán reenviar una nueva versión del artículo, atendiendo a las demandas y sugerencias de los evaluadores externos. Si lo desean, los autores pueden aportar también una carta al Consejo Editorial en la que indicarán el contenido de las modificaciones del artículo. Los artículos con correcciones importantes podrán ser remitidos al Consejo Asesor y/o Científico para verificar la validez de las modificaciones efectuadas por el autor

EXTERNAL ANONYMOUS PEER REVIEW.

When the Editorial Board of the magazine has verified that the article fulfils the standards relating to style and content indicated in the instructions for authors, the article will be sent to two anonymous experts, within the specific field of architectural investigation and critique, for a double blind review.

The Director of the magazine will communicate the result of the reviewers' evaluations, and their recommendations, to the authors by electronic mail, to the address used to send the article. The Director will communicate the result of the review (publication without changes; publication with minor corrections; publication with significant corrections; its publication is not advisable), as well as the observations and comments of the reviewers, to the main author.

If the manuscript has been accepted with modifications, the authors will have to resubmit a new version of the article, addressing the requirements and suggestions of the external reviewers. If they wish, the authors can also send a letter to the Editorial Board, in which they will indicate the content of the modifications of the article. The articles with significant corrections can be sent to Advisory and/or Scientific Board for verification of the validity of the modifications made by the author.

\section{INSTRUCCIONES A AUTORES PARA LA REMISIÓN DE ARTÍCULOS}

NORMAS DE PUBLICACIÓN

Instrucciones a autores: extensión máxima del artículo, condiciones de diseño -márgenes, encabezados, tipo de letra, cuerpo del texto y de las citas-, composición primera página, forma y dimensión del título y del autor/a, condiciones de la reseña biográfica, del resumen, de las palabras claves, de las citas, de las imágenes -numeración en texto, en pié de imágenes, calidad de la imagen y autoría o procedencia- y de la bibliografía en http://www.proyectoprogresoarquitectura.com (> PARTICIPA > POLITICA DE SECCIONES Y NORMAS DE REDACCIÓN / NORMAS BIBLIOGRAFÍA Y CITAS)

PUBLICATION STANDARDS

Instructions to authors: maximum length of the article, design conditions (margins, headings, font, body of the text and quotations), composition of the front page, form and size of the title and the name of the author, conditions of the biographical review, the summary key words, quotations, images (text numeration, image captions, image quality and authorship or origin) and of the bibliography in http://www.proyectoprogresoarquitectura.com (> PARTICIPA > POLÍTICA DE SECCIONES Y NORMAS DE REDACCIÓN / NORMAS BIBLIOGRAFÍA Y CITAS) 


\section{SERVICIOS DE INFORMACIÓN}

\section{CALIDAD EDITORIAL}

La Editorial Universidad de Sevilla cumple los criterios establecidos por la Comisión Nacional Evaluadora de la Actividad Investigadora para que lo publicado por el mismo sea reconocido como "de impacto" (Ministerio de Ciencia e Innovación, Resolución 18939 de 11 de noviembre de 2008 de la Presidencia de la CNEAI, Apéndice I, BOE nº 282, de 22.11.08).

La Editorial Universidad de Sevilla forma parte de la U.N.E. (Unión de Editoriales Universitarias Españolas) ajustándose al sistema de control de calidad que garantiza el prestigio e internacionalidad de sus publicaciones.

\section{PUBLICATION QUALITY}

The Editorial Universidad de Sevilla fulfils the criteria established by the National Commission for the Evaluation of Research Activity (CNEAl) so that its publications are recognised as "of impact" (Ministry of Science and Innovation, Resolution 18939 of 11 November 2008 on the Presidency of the CNEAl, Appendix I, BOE No 282, of 22.11.08).

The Editorial Universidad de Sevilla operates a quality control system which ensures the prestige and international nature of its publications, and is a member of the U.N.E. (Unión de Editoriales Universitarias Españolas-Union of Spanish University Publishers).

Los contenidos de la revista PROYECTO, PROGRESO, ARQUITECTURA aparecen en:

\section{bases de datos: indexación}

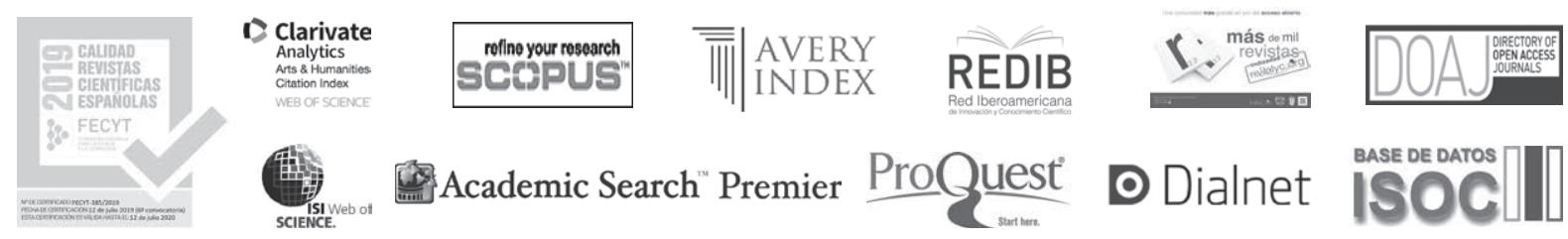

\section{SELLO DE CALIDAD EDITORIAL FECYT 2019}

WoS. Arts \& Humanities Citation Index WoS. ESCl - Emerging Sources Citation Index SCOPUS

AVERY. Avery Index to Architectural Periodicals

REBID. Red Iberoamericana de Innovación y Conocimiento Científico

REDALYC. Red de Revistas Científicas de América Latina y el Caribe, España y Portugal.

EBSCO. Fuente Académica Premier

EBSCO. Art Source

DOAJ, Directory of Open Access Journals

PROQUEST (Arts \& Humanities, full text)

DIALNET

ISOC (Producida por el CCHS del CSIC)

DRIJ. Directory of Research Journals Indexing

SJR (2018): 0.111, H index: 2 CUARTIL: Q3

\section{catalogaciones: criterios de calidad}

RESH (Revistas Españolas de Ciencias Sociales y Humanidades).

Catálogos CNEAI (16 criterios de 19). ANECA (18 criterios de 21). LATINDEX (35 criterios sobre 36).

DICE (CCHS del CSIC, ANECA)

MIAR, Matriu d'Informació per a l'Avaluació de Revistes. IDCS 2018: 10,500. Campo ARQUITECTURA

CLASIFICACIÓN INTEGRADA DE REVISTAS CIENTÍFICAS (CIRC-CSIC): A

ERIHPLUS

SCIRUS, for Scientific Information.

ULRICH'S WEB, Global Serials Directory.

ACTUALIDAD IBEROAMERICANA.

catálogos on-line bibliotecas notables de arquitectura:

CLIO. Catálogo on-line. Columbia University. New York

HOLLIS. Catálogo on-line. Harvard University. Cambridge. MA

SBD. Sistema Bibliotecario e Documentale. Instituto Universitario di Architettura di Venezia

OPAC. Servizi Bibliotecari di Ateneo. Biblioteca Centrale. Politecnico di Milano

COPAC. Catálogo colectivo (Reino Unido)

SUDOC. Catálogo colectivo (Francia)

ZBD. Catálogo colectivo (Alemania)

REBIUN. Catálogo colectivo (España)

OCLC. WorldCat (Mundial) 


\section{DECLARACIÓN ÉTICA SOBRE PUBLICACIÓN Y MALAS PRÁCTICAS}

La revista PROYECTO, PROGRESO, ARQUITECTURA (PPA) está comprometida con la comunidad académica en garantizar la ética y calidad de los artículos publicados. Nuestra revista tiene como referencia el Código de Conducta y Buenas Prácticas que, para editores de revistas científicas, define el COMITÉ DE ÉTICA DE PUBLICACIONES (COPE).

Así nuestra revista garantiza la adecuada respuesta a las necesidades de los lectores y autores, asegurando la calidad de lo publicado, protegiendo y respetando el contenido de los artículos y la integridad de los mismo. El Consejo Editorial se compromete a publicar las correcciones, aclaraciones, retracciones y disculpas cuando sea preciso.

En cumplimiento de estas buenas prácticas, la revista PPA tiene publicado el sistema de arbitraje que sigue para la selección de artículos así como los criterios de evaluación que deben aplicar los evaluadores externos -anónimos y por pares, ajenos al Consejo Editorial-. La revista PPA mantiene actualizados estos criterios, basados exclusivamente en la relevancia científica del artículo, originalidad, claridad y pertinencia del trabajo presentado.

Nuestra revista garantiza en todo momento la condifencialidad del proceso de evaluación: el anonimato de los evaluadores y de los autores; el contenido evaluado; los informes razonados emitidos por los evaluadores y cualquier otra comunicación emitida por los consejos Editorial, Asesor y Científico si así procediese.

Igualmente quedan afectados de la máxima confidencialidad las posibles aclaraciones, reclamaciones o quejas que un autor desee remitir a los comités de la revista o a los evaluadores del artículo.

La revista PROYECTO, PROGRESO, ARQUITECTURA (PPA) declara su compromiso por el respeto e integridad de los trabajos ya publicados. Por esta razón, el plagio está estrictamente prohibido y los textos que se identifiquen como plagio o su contenido sea fraudulento, serán eliminados o no publicados por la revista PPA. La revista actuará en estos casos con la mayor celeridad posible. Al aceptar los términos y acuerdos expresados por nuestra revista, los autores han de garantizar que el artículo y los materiales asociados a él son originales o no infringen derechos de autor. También los autores tienen que justificar que, en caso de una autoría compartida, hubo un consenso pleno de todos los autores afectados y que no ha sido presentado ni publicado con anterioridad en otro medio de difusión.

\section{ETHICS STATEMENT ON PUBLICATION AND BAD PRACTICES}

PROYECTO, PROGRESO ARQUITECTURA (PPA) makes a commitment to the academic community by ensuring the ethics and quality of its published articles. As a benchmark, our journal uses the Code of Conduct and Good Practices which, for scientific journals, is defined for editors by the PUBLICATION ETHICS COMMITTEE (COPE).

Our journal thereby guarantees an appropriate response to the needs of readers and authors, ensuring the quality of the published work, protecting and respecting the content and integrity of the articles. The Editorial Board will publish corrections, clarifications, retractions and apologies when necessary.

In compliance with these best practices, PPA has published the arbitration system that is followed for the selection of articles as well as the evaluation criteria to be applied by the anonymous, external peer-reviewers. PPA keeps these criteria current, based solely on the scientific importance, the originality, clarity and relevance of the presented article.

Our journal guarantees the confidentiality of the evaluation process at all times: the anonymity of the reviewers and authors; the reviewed content; the reasoned report issued by the reviewers and any other communication issued by the editorial, advisory and scientific boards as required.

Equally, the strictest confidentiality applies to possible clarifications, claims or complaints that an author may wish to refer to the journal's committees or the article reviewers.

PROYECTO, PROGRESO ARQUITECTURA (PPA) declares its commitment to the respect and integrity of work already published. For this reason, plagiarism is strictly prohibited and texts that are identified as being plagiarized, or having fraudulent content, will be eliminated or not published in PPA. The journal will act as quickly as possible in such cases. In accepting the terms and conditions expressed by our journal, authors must guarantee that the article and the materials associated with it are original and do not infringe copyright. The authors will also have to warrant that, in the case of joint authorship, there has been full consensus of all authors concerned and that the article has not been submitted to, or previously published in, any other media. 
PROYECTO, PROGRESO, ARQUITECTURA. N21, NOVIEMBRE 2019 (AÑO X)

\section{paisaje de bancales}

índice

editorial

ARQUITECTURA DE LA MONÓTONA REPETICIÓN. PAISAJE DE BANCALES / ARCHITECTURE OF THE MONOTTON REPETITION. TERRACES LANDSCAPES

Juan Manuel Palerm Salazar - (DOI: http://dx.doi.org/10.12795/ppa.2019.121.12

entre líneas

ATAPTED SLOPES

Lucija Ažman Momirskis - (DOl: http://dx.doi.org/10.12795/ppa.2019.i21.01)

artículos

BANCALES HABITADOS: DE LA REUTILIZACIÓN EN LA ARQUITECTURA TRADICIONAL AL TRABAJO CON EL TIEMPO DE CÉSAR MANRIQUE Y SOUTO DE MOURA / FLIVING TERRACES: FROM REUSE IN TRADITIONAL ARCHITECTURE TO CÉSAR MANRIQUE AND SOUTO DE MOURA'S WORK WITH TIME

Francisco Javier Castellano Pulido - (DOI: http://dx.doi.org/10.12795/ppa.2019.121.02)

ESTRATEGIAS TERRITORIALES INTEGRALES PARA LA PUESTA EN VALOR DE PAISAJE CULTURAL AGRÍCOLA. LA RIBEIRA SACRA, GALICIA, ESPAÑA / COMPREHENSIVE TERRITORIAL STRATEGIES TO ENHANCE THE AGRICULTURAL-CULTURAL LANDSCAPE. RIBEIRA SACRA, GALICIA, SPAIN

Susana López Varela - (D0I: http://dx.doi.org/10.12795/ppa.2019.i21.03)

PAISAJES DE ALTURA: LOS ANDENES DEL DISTRITO DE CABANA, VALLE DEL SONDONDO, PERÚ / HIGH LANDSCAPES: THE ANDENES OF THE DISTRIT OF CABANA, SONDONDO VALLEY, PERU Sonia Delgado Berrocal - (DOl: http://dx.doi.org/10.12795/ppa.2019.i21.04)

COLTIVARE I TERRAZZAMENTI AI PIEDI DEL MONTE BIANCO. LA "VITICOLTURA EROICA" DI MORGEX / CULTIVATING THE TERRACES AT THE FOOT OF MONT BLANC. THE "HEROIC VITICULTURE" OF MORGEX

Beatrice Agulli - (DOl: http://dx.doi.org/10.12795/ppa.2019.121.05)

SIAH DAREH. TERRAZAS Y PAISAJE EN ABBAS KIAROSTAMI / SIAH DAREH. TERRACES AND LANDSCAPE IN ABBAS KIAROSTAMI

Pablo López Santana - (DOl: http://dx.doi.org/10.12795/ppa.2019.121.06)

FRANK LLOYD WRIGHT. TRABAJAR LA TIERRA PARA UN PAISAJE SIMBIÓTICO / FRANK LLOYD WRIGHT. EARTHWORK FOR A SYMBIOTIC LANDSCAPE

José María Jové Sandoval - (D0l: http://dx.doi.org/10.12795/ppa.2019.i21.07)

ROGELIO SALMONA Y LA CONSTRUCCIÓN DEL LÍMITE. DIÁLOGOS ENTRE TOPOGRAFÍA Y PAISAJE / ROGELIO SALMONA AND THE CONSTRUCTION OF LIMITS. DIALOGUES BETWEEN TOPOGRAPHY AND LANDSCAPE

Clara Mejía Vallejo; Ricardo Merí de la Maza - (D0l: http://dx.doi.org/10.12795/ppa.2019.i21.08)

reseña bibliográfica TEXTOS VIVOS

RODRIGO ALMONACID CANSECO: EL PAISAJE CODIFICADO EN LA ARQUITECTURA DE ARNE JACOBSEN

Carlos Santamarina-Macho - (DOI: http://dx.doi.org/10.12795/ppa.2019.i21.09)

JAVIER MADERUELO: EL PAISAJE. GÉNESIS DE UN CONCEPTO

Victoriano Sainz Gutiérrez - (DOI: http://dx.doi.org/10.12795/ppa.2019.121.10)

GEORG SIMMEL: FILOSOFÍA DEL PAISAJE

Esther Mayoral Campa - (DOI: http://dx.doi.org/10.12795/ppa.2019.i21.11)

VERSIÓN EN INGLÉS A TEXTO COMPLETO DE TODOS LOS ARTICULOS, EN LA EDICIÓN ON-LINE https://revistascientificas.us.es/index.php/ppa y http://www.proyectoprogresoarquitectura.com/ 


\title{
BANCALES HABITADOS: DE LA REUTILIZACIÓN EN LA ARQUITECTURA TRADICIONAL AL TRABAJO CON EL TIEMPO DE CÉSAR MANRIQUE Y SOUTO DE MOURA
}

\author{
LIVING TERRACES: FROM REUSE IN TRADITIONAL ARCHITECTURE TO CÉSAR MANRIQUE \\ AND SOUTO DE MOURA'S WORK WITH TIME
}

Francisco Javier Castellano Pulido (https://orcid.org/0000-0002-9287-1983)

RESUMEN En las últimas décadas del siglo XX, el especial interés que demostraron arquitectos como César Manrique y Eduardo Souto de Moura por el paisaje de terrazas agrícolas, utilizándolas como argumento para la integración de sus obras en el medio, permitió recuperar ciertas estrategias de transferencia entre agricultura y arquitectura propias de la arquitectura tradicional. E hábitat troglodita en la ciudad excavada de Matera, la continuidad de los bancales pétreos incas de Machu Picchu o la evolución de la terraza irrigada del Generalife constituyen claros ejemplos de la lógica de un proceso de transformación que no distingue entre disciplinas. La consideración de estos elementos del patrimonio mundial, puestos en relación con ciertas obras emblemáticas de la arquitectura contemporánea, permite apreciar la reciente incorporación de estrategias de intervención que amplían significativamente la posibilidad de transformación sensible del medio agrícola para el espacio habitable. A través del uso de nuevos materiales, resulta viable la conversión de las terrazas agrícolas en paisajes donde la arquitectura, el territorio, la ruina y el cultivo se confunden. La consideración del bancal en la memoria del territorio y en el trabajo con el tiempo, por otra parte, sugiere la necesidad de renovar un patrimonio vivo, a menudo carente de toda protección, que podría conformar, en diálogo con la arquitectura actual, un nuevo legado para el futuro.

PALABRAS CLAVE infraestructuras agrícolas; memoria; patrimonio agrícola; bancales.

ABSTRACT In the last decades of the 20th century, the special interest shown by architects such as César Manrique and Eduardo Souto de Moura in terraced agricultural landscapes, using them as an argument for the integration of their works in the environment, made it possible to revive certain transference strategies between agriculture and architecture commonly found in traditional architecture. The troglodyte habitat in the excavated city of Matera, the continuity of the Inca stone terraces of Machu Picchu or the evolution of the irrigated terrace of the Generalife are clear examples of the logic of a transformation process that does not distinguish between disciplines. The consideration of these elements of World Heritage, placed in relation to certain emblematic works of contemporary architecture, allows us to appreciate the recent incorporation of intervention strategies that significantly extend the possibility of sensitive transformation of the agricultural environment into living space. The use of new materials enables the conversion of agricultural terraces into landscapes where architecture, territory, ruins and cultivation come together. Considering the terraces as part of the memory of the territory and in work about time, on the other hand, suggests the need to renew a living heritage, often lacking any protection, which could form, in dialogue with current architecture, a new legacy for the future.

KEYWORDS agricultural infrastructure; memory; agricultural heritage; terraces

Persona de contacto / Corresponding author: javiercastellano@uma.es Escuela Técnica Superior de Arquitectura. Universidad de Málaga. España 
PROYECTO, PROGRESO, ARQUITECTURA

os procesos de crecimiento orgánico de la ciudad preindustrial, según algunas investigaciones realizadas en la década de 1970 por el arquitecto y profesor italiano Gianfranco Caniggia, permitieron integrar la cultura agrícola y sus sistemas como parte de sus procesos de cambio, dotando al lugar de contenidos y dinámicas abiertas a transformaciones graduales del territorio ${ }^{1}$. Este autor lo atribuía a la que denominó conciencia espontánea, definiéndola como "la aptitud de un sujeto actuante para adaptarse, en su actuación, a la esencia cultural heredada, sin necesidad ni obligatoriedad de mediaciones o de decisiones" ${ }^{2}$. Juan Luis Trillo señalaba algo parecido sobre la tradición en la arquitectura, producto de una labor comunal en la que algunos operarios interpretaban el sentir general, permitiendo "la continuidad en un doble sentido, en la secuencialidad temporal de la arquitectura y en la homogeneidad sincrónica del paisaje"3. La continuidad y homogeneidad se encuentra relacionada con lo que algunos autores denominan la cualidad cohesiva de la arquitectura popular, que puede aplicarse tanto a la construcción del paisaje agrícola como al desarrollo arquitectónico y urbano:

"El hombre rural vivía en armonía con su paisaje, adecuándose al entorno tanto en lo que respecta a su actividad productiva, la agricultura, como en lo que respecta a sus construcciones vivideras. El cuidado de la tierra como sustento y forma de vida resultaba esencial para el desarrollo de estas comunidades. Por ello, el acercamiento desde el clima, la topografía o los materiales autóctonos era una práctica intrínseca al modo de hacer popular"4.

A partir de la década de 1960, gracias a una conciencia cada vez mayor del grado de irreversibilidad que podían producir las acciones humanas sobre el medio ambiente, emergió una nueva sensibilidad hacia el paisaje

1. Gianfranco Caniggia continuaba, de algún modo, la perspectiva territorial desarrollada por su maestro Saverio Muratori, cuyo discurso especulativo sobre la crisis del territorio y la arquitectura, iniciado en 1962, pudo encontrar respuesta en Civiltà e territorio, animando a una cierta autoconsciencia de las obras arquitectónicoas dentro de un equilibrio global del territorio. Véase MURATORI, S. Civiltà e territorio. Roma: Centro Studi di Storia Urbanistica, 1967. 2. CANIGGIA, Gianfranco; GIAN LUIGI, Maffei. Tipología de la edificación: estructura del espacio antrópico. Madrid: Celeste Ediciones, 1979, p. 24. 3. TRILLO DE LEYVA, Juan Luis. Argumentos sobre la contigüidad en arquitectura. Sevilla: Editorial Universidad de Sevilla, 2001, p. 132 4. ARCARAZ PUNTONET, Jon. La construcción del paisaje. Plan Parcial de Urbanización de Lanzarote. 1963. En: ZARCH: Journal of interdisciplinary studies in Architecture and Urbanism, 2016, n. ${ }^{\circ}$ 7, p. 91. ISSN 2341-0531. 
agrario por parte de los arquitectos y los artistas, destacando la singularidad de los bancales. Pero esta sensibilidad, que podríamos llamar ecológica y ambiental, no llegó a impregnar la disciplina de proyectos en todas sus dimensiones, salvo algunas excepciones ${ }^{5}$. Frente a la ausencia de la conciencia espontánea, parece necesaria la adquisición de la conciencia crítica que reclamaba Caniggia para las nuevas obras de arquitectura. Así, para el proyecto contemporáneo resulta útil la búsqueda de experiencias de la arquitectura histórica en las que se produce algún tipo de intercambio entre las preexistencias agrícolas del lugar o sus proximidades y los programas arquitectónicos previstos. Entre estos ejemplos, las terrazas de cultivo ocupan un lugar privilegiado, por su capacidad para ordenar el territorio mejorando la fertilidad de la tierra y por la impronta que confieren al paisaje.

Sobre esta pista nos coloca el arquitecto Juan Luis Trillo en su ensayo Argumentos sobre la contigüidad en arquitectura ${ }^{6}$, un estimulante alegato sobre la actividad especulativa que vuelve a abrir el debate sobre el papel del patrimonio en el proyecto contemporáneo. Su interés se dirige hacia los procesos creativos que llevan a la traslación de cualidades de unas formas, materias o ideas a otras, identificando estrategias de aproximación que denomina de mínima energía, también llamada economía de medios o ley de máxima economía interna, que se traduce "en la elección del camino más breve entre las formas resultantes y las iniciales y en la reutilización de los materiales"7. Según este autor, estas operaciones conceptuales — guiadas por relaciones de contigüidad - pueden extrapolarse a toda actividad proyectual y, sobre todo, parecen "reproponer un campo más amplio de operaciones, en relación con los bienes patrimoniales"8. Más allá de conceptos rígidos, nos brinda una forma de leer el pasado que permite la articulación de continuidad y discontinuidad, atendiendo a los procesos y las relaciones que somos capaces de descubrir entre realidades de distinto orden. En el caso del tratamiento de los jardines resulta fácil afirmarlo, pues su desarrollo se basa en procedimientos e imágenes agrícolas que son realzadas, es decir, el trasvase de conceptos se percibe como algo natural:

"Los claros en un bosque o las floridas praderas de hierba se convirtieron en el césped de hierba. Los canales ornamentales en los jardines holandeses fueron una extensión estética de las zanjas de drenaje en los polders de las tierras bajas. Las terrazas se derivaron de las laderas adaptadas para la agricultura (...). De manera similar, las fuentes y los sistemas hidráulicos surgieron de las necesidades de riego y las técnicas de elaboración de los jardines de allées y bosquetes —arboledas - fue desarrollada a partir de la gestión del técnico forestal de bosques y de los territorios de caza".

Las transferencias o préstamos materiales y formales entre los paisajes de bancales y la arquitectura, en cambio, no son exclusivas del diseño de los jardines, se encuentran presentes en la conformación de arquitecturas reconocidas por su integración en el medio, como puede verse en algunos de los lugares más emblemáticos del Patrimonio de la Humanidad, como es el caso del Santuario Histórico de Machu Picchu, en Perú, el conjunto de la Alhambra y el Generalife, en Granada, y los Sassi de Matera de la región italiana de Basilicata, inscritos por la UNESCO en los años 1983, 1984 y 1993, respectivamente.

\section{TRANSFERENCIAS E INTERCAMBIOS ENTRE LAS TERRAZAS AGRÍCOLAS Y LA ARQUITECTURA TRADICIONAL: EL EJEMPLO DE MATERA, MACHU PICCHU Y EL GENERALIFE}

El proceso evolutivo de las terrazas agrícolas de la cultura incaica constituye un caso paradigmático de transferencia por contigüidad constructiva gracias a procesos de reutilización de materiales y técnicas que llevaron a la

5. CASTELLANO PULIDO, Francisco Javier. El patrimonio fértil. Transferencias entre el paisaje agrario y la arquitectura en los crecimientos urbanos. Tesis doctoral. Universidad de Granada, 2015.

6. TRILLO DE LEYVA, Juan Luis, op. cit. supra, nota 2, p. 132.

7. TRILLO DE LEYVA, Juan Luis, op. cit. supra, nota 2, p. 21.

8. Según Trillo, esta extrapolación a la arquitectura puede llevarse a través del concepto de fabulación. TRILLO DE LEYVA, Juan Luis, op. cit. supra, nota 2, p. 76. 9. DIXON HUNT, John. Greater perfections: the practice of garden theory. Londres: Thames \& Hudson, 2000, p. 85. Traducción propia. 
adquisición de una dimensión simbólica de gran relevancia para la arquitectura. Las terrazas eran plataformas horizontales construidas con bajos muros de contención de piedra, constituyendo un sistema altamente productivo $^{10}$. Las estrategias constructivas derivadas de este sistema se extendieron por las zonas altas, lo que requería de su adaptación a una topografía cada vez más compleja. En el trascurso de este desplazamiento ladera arriba, la pendiente se hacía más acusada y la altura de los muros de las plataformas agrícolas podía adquirir mayores dimensiones, transformándose en verdaderas estructuras arquitectónicas de escala y representación urbana (figura 1) ${ }^{11}$.

En este movimiento ascendente, uno de los distintos tipos de andenes o bancales construidos - los denominados de alto prestigio ${ }^{12}$ - , se densificaban tanto que dejaban de tener un valor realmente productivo, es decir, la pendiente de la ladera era tan acusada que las terrazas se volvían muy estrechas y el aumento de productividad de su superficie no compensaba el esfuerzo por construirlas. La fuerte impronta que estos bancales tenían en el territorio, en cambio, permitía utilizarlos con fines representativos, facilitando su traducción al lenguaje simbólico de la arquitectura ${ }^{13}$ (figuras 2 y 3). El traslado de las técnicas constructivas del conjunto se evidencia aquí a través de un desplazamiento técnico y formal desde lo agrícola a lo arquitectónico de gran trascendencia para la cultura incaica. De hecho, las terrazas agrícolas no solo llegaron a ser la principal forma de arquitectura del territorio, sino que se convirtieron en la forma más significativa de evidenciar la ocupación humana.

El caso de los Sassi de Matera, de la región italiana de Basilicata, al igual que otros asentamientos del altiplano de las Murge, constituye un ejemplo singular de forma de urbanización que ha permitido a lo largo del tiempo su crecimiento e intensificación sin perder la matriz agropastoral original. Su principal trazado responde tanto a la necesidad de aprovechamiento del agua como a la energía disponible y a la protección del suelo, ineludible para la sostenibilidad de todo el sistema ${ }^{14}$. De este modo, distintas culturas supieron aprovechar los bordes de gargantas estrechas y profundas llamadas gravinas, con pocas aportaciones hídricas, para la creación de un oasis pétreo de origen prehistórico de gran expresividad. Como puede verse en la figura 4, la arquitectura se desarrolla de forma cohesiva con las infraestructuras hídricas, produciéndose una síntesis física capaz de integrar estrategias troglodíticas para la captación de agua con la construcción de terrazas o bancales que, gracias a procesos de reutilización y reciclaje, han podido constituir la base de las transformaciones urbanas posteriores. Esta lógica constructiva de mínima energía parece haberse mantenido en el tiempo: si desde la prehistoria se utilizaba el material de la propia excavación en la roca en las nuevas construcciones o para ampliar y abancalar las laderas, en la Edad Media se llevaron a cabo procesos de transformación que permitieron la conversión de graneros hipogeos en iglesias y de silos o cisternas en viviendas. En la actualidad, aún se conservan algunos huertos —llamados eras-jardín o terrazas colgantesque sirven de testimonio del interesante ecosistema urbano que ha conseguido sostenerse en el tiempo gracias al constante proceso de reutilización e interpretación de su matriz hidroagrícola. En este proceso de crecimiento cohesivo, toda forma urbana responde, de algún modo, a la posibilidad de transformación más eficiente del paisaje irrigado original:

"El huerto irrigado y el área pastoril se transformaron en lugares de reunión de la familia extensa (...). La gran cisterna comunitaria que recoge el agua que cae de los

10. Sobre la productividad del sistema de andenes, véase KAUFFMANN DOIG, Federico. Historia y arte del Perú antiguo. Lima: Ediciones Peisa-La RepúblicaGloria, 2002.

11. HYSLOP, John. Inka settlement planning. Austin: University of Texas Press, 1990.

12. Susan A. Niles, en su estudio sobre las obras agrícolas cerca de Cusco (Cuzco), distinguió diversos tipos de andenes a partir de las técnicas constructivas empleadas - de producción, de alto prestigio y mixtos- 0 a partir de su uso -agrícolas, experimentales 0 científicos y salineros-. NILES, Susan A. Style and function in inca agricultural works near Cuzco. En: Ñawpa Pacha: Journal of Andean Archaeology, 1982, n. . 20, pp. 163-182. ISSN 0077-6297.

13. Véase MÚJICA, Elías. Andenes. Arquitectura productiva inca. En: Revista Arkinka. Lima: Arkinka, 1996, n. ${ }^{\circ}$ 3, ISSN 1815-9273.

14. LAUREANO, Pietro. Atlas de agua: Ios conocimientos generales para combatir la desertificación. Barcelona: Laia, 2005, p. 156. 


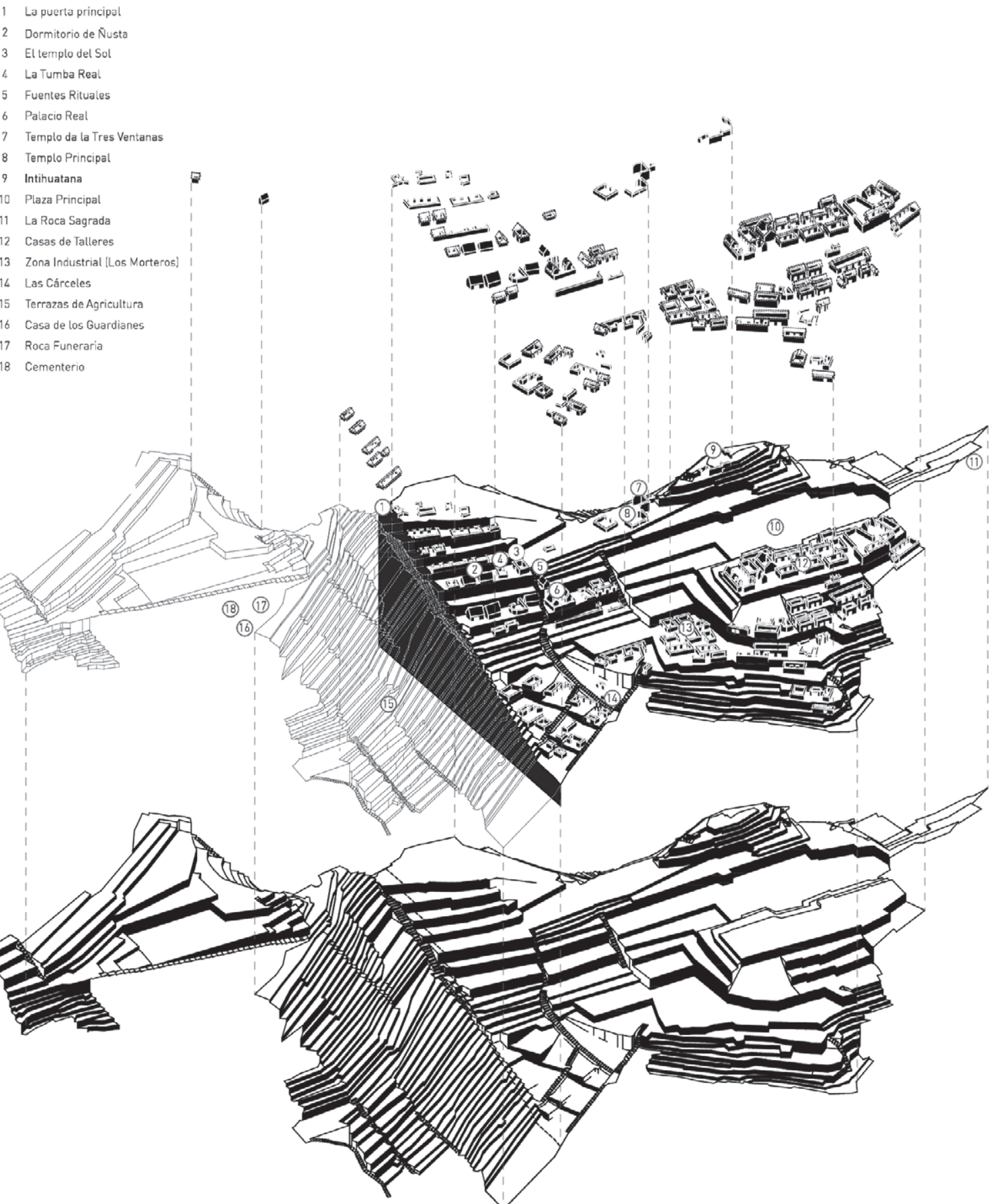

1. Perspectiva de Machu Picchu mostrando la relación entre las terrazas agrícolas y la arquitectura. 2 y 3. Descubrimiento de Machu Picchu, 1912. Izquierda: panorámica general; derecha: vista del sector agrícola.

4. Esquema del ecosistema urbano de los Sassi de Matera sobre el paisaje de bancales. Redibujado a partir del Atlas de agua, de Pietro Laureano.

Principales terrazas agricolas

3.12 Persoectiva descompuesta de Machu Pichu.

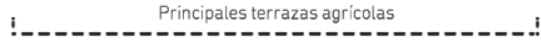

3.13 Vista de Machu Pichu 
PROYECTO, PROGRESO, ARQUITECTURA
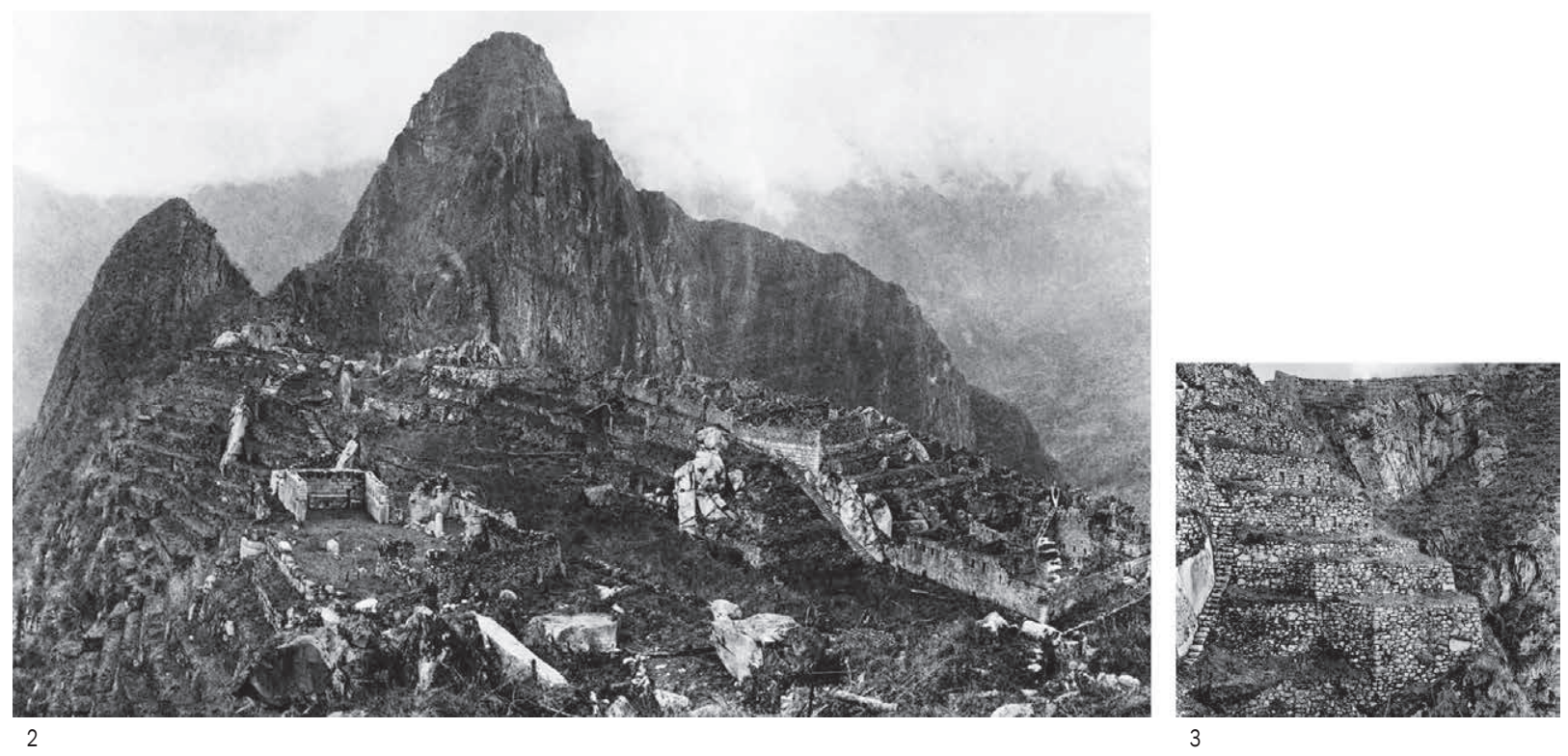

3

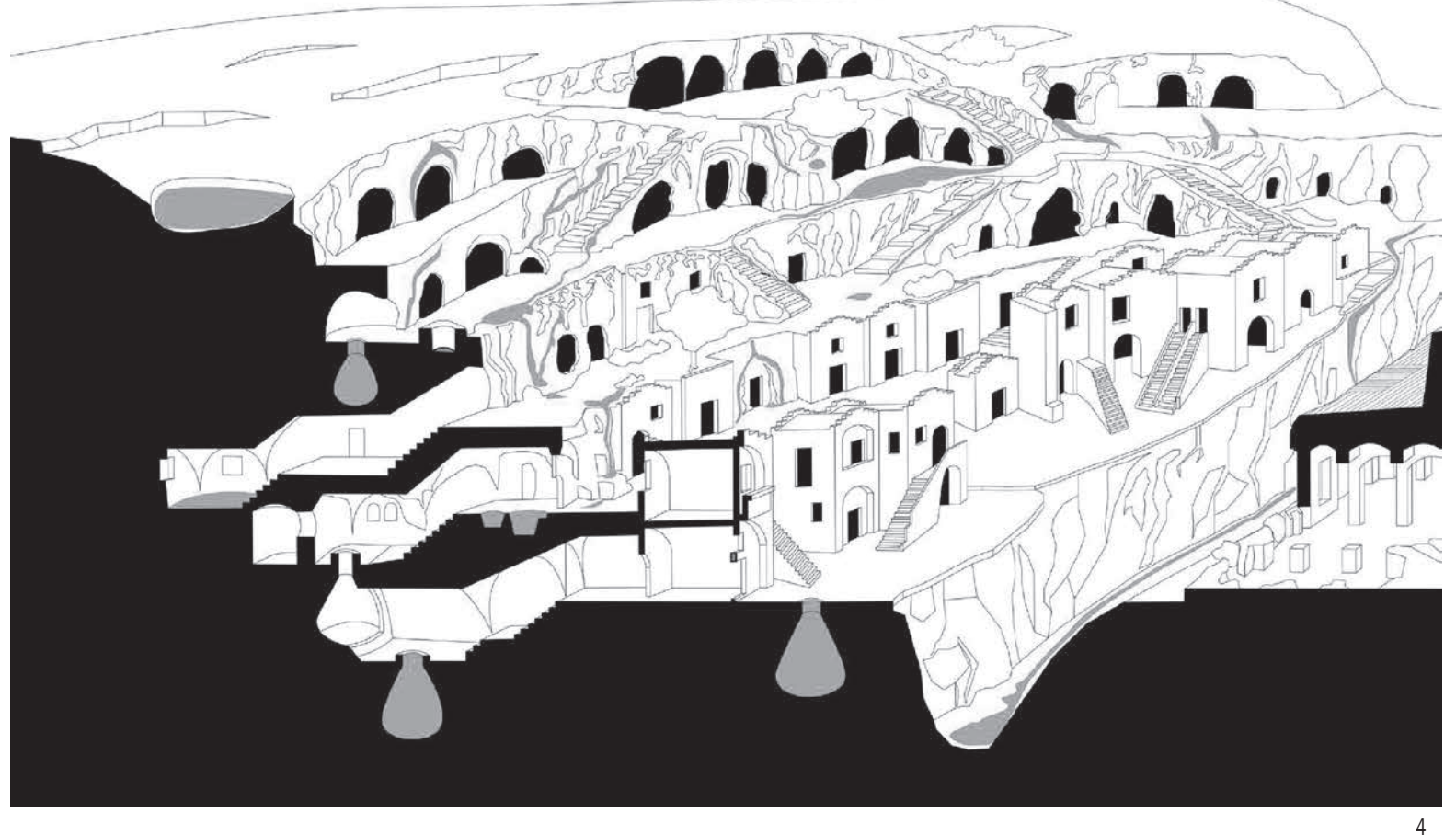

techos se excavó en el patio central. El techo es construido dentro de los muros, lo que permite no desperdiciar una sola gota de lluvia, que es conducida a la cisterna a través de canales de terracota. El escalón superpuesto se convierte en un jardín colgante. Las canales laterales de drenaje se transforman en escaleras y conexiones verticales dentro del conjunto urbano. La trama de las callejuelas deriva de su adhesión al sistema de canales..." 15 .

El conjunto monumental del Generalife, en Granada, constituye un caso paradigmático de transformación de un paisaje agrícola de bancales de origen islámico medieval a partir de las infraestructuras agrícolas

15. Ibíd., p. 204. 
5. Patio de la Acequia. El Generalife, Granada, 2019. 6. Generalife. Sección transversal del palacio y jardines altos.

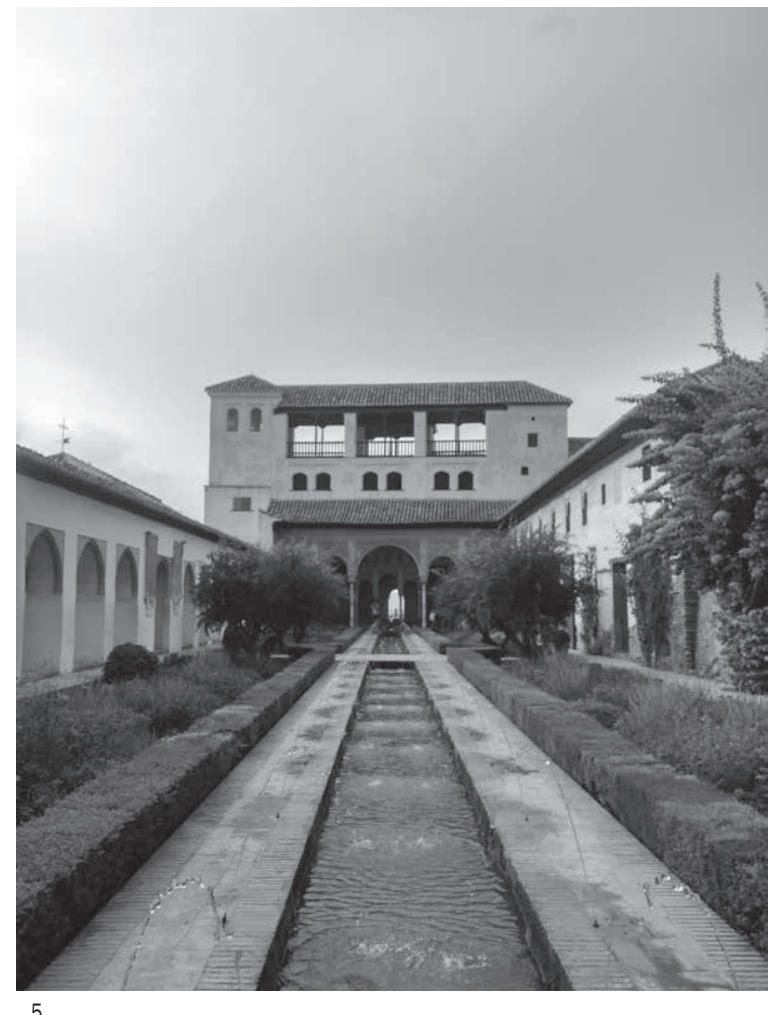

preexistentes. En esta residencia de descanso del sultán, situada fuera de las murallas de la Alhambra, el proceso de integración de construcciones en terrazas agrícolas posee como elemento unificador el agua. A semejanza de otras almunias situadas alrededor de la ciudad, se trata de una finca con residencia propia de la tradición mediterránea que era utilizada para la producción y el recreo. La ladera en la que se sitúa, carente de manantiales naturales, necesitó de un sistema de riego sofisticado que permitiría la conducción del agua a la fortaleza de la Alhambra, abriendo así la posibilidad de la conformación de jardines y huertas. La Acequia Real puede considerarse como una de las construcciones primordiales para la construcción del paisaje aterrazado del conjunto paisajístico que hoy reconocemos por su alto valor productivo y patrimonial ${ }^{16}$. Esta infraestructura hídrica nazarí toma su agua desde una derivación del río Darro a seis kilómetros de la Alhambra, bifurcándose en la Acequia del Tercio, que conduce el agua por una cota superior para regar las zonas agrícolas más altas y la Acequia Dos Tercios, que discurre por debajo hasta volver a la principal. Sobre la acequia inferior se sitúa una de las edificaciones del palacio del Generalife, que la integra en el eje principal de su patio, el llamado Patio de la Acequia (figura 5) ${ }^{17}$.

Es posible apreciar en la evolución del Generalife un cierto respeto por las trazas y elementos pertenecientes a las antiguas edificaciones e infraestructuras agrícolas (figura 7). Se puede ver aquí una delicada asimilación por parte de la arquitectura islámica de las acequias, los estanques ${ }^{18}$, los muros de la edificación preexistente y los bancales agrícolas, alineando los trazados de las nuevas construcciones a las terrazas y tomando las proporciones alargadas de la conducción de agua para su patio principal. Este lugar central permite dotar a la acequia de una función simbólica propia de las albercas en otros recintos de la Alhambra. En los jardines altos (figura 6) puede apreciarse también un progresivo proceso de refinamiento en el sistema de ajardinamiento que alcanza el siglo XV y que extiende la misma lógica de las terrazas irrigadas ladera arriba, tomando como partida algunos huertos preexistentes conectados a través de la llamada Escalera de Agua.

En el conjunto paisajístico conformado por el Generalife resulta especialmente interesante el proceso de

16. Según algunos autores, parece probable que el aterrazamiento de los terrenos situados debajo de esta acequia se produjera de forma posterior a la creación de la Acequia Real a partir de las obras del fundador de la dinastía nazarí Muhammad I (1238-1272). TITO ROJO, José; CASARES PORCEL, Manuel. El jardín hispanomusulmán: los jardines de al-Andalus y su herencia. Granada: Universidad de Granada, 2011, p. 228.

17. Véase ORIHUELA UZAL, Antonio; RODRÍGUEZ MORENO, Miguel. Casas y palacios nazaríes: siglos XIII-XV. Sevilla: Junta de Andalucía, Consejería de Cultura, Consejería de Turismo y Deporte; Granada: El Legado Andalusí; Barcelona: Lunwerg Editores, 1996. También VÍLCHEZ VÍLCHEZ, Carlos. El Generalife. Granada: Proyecto Sur, 1991, p. 31.

18. El estanque del Patio de la Sultana, nombrado previamente Estanque de los Peces, formaba parte del sistema hidroagrícola y era, por su ubicación, el más antiguo de la finca, probablemente, anterior al Albercón de las Damas. TITO ROJO, José; CASARES PORCEL, Manuel, op. cit. supra, nota 15, p. 394. 


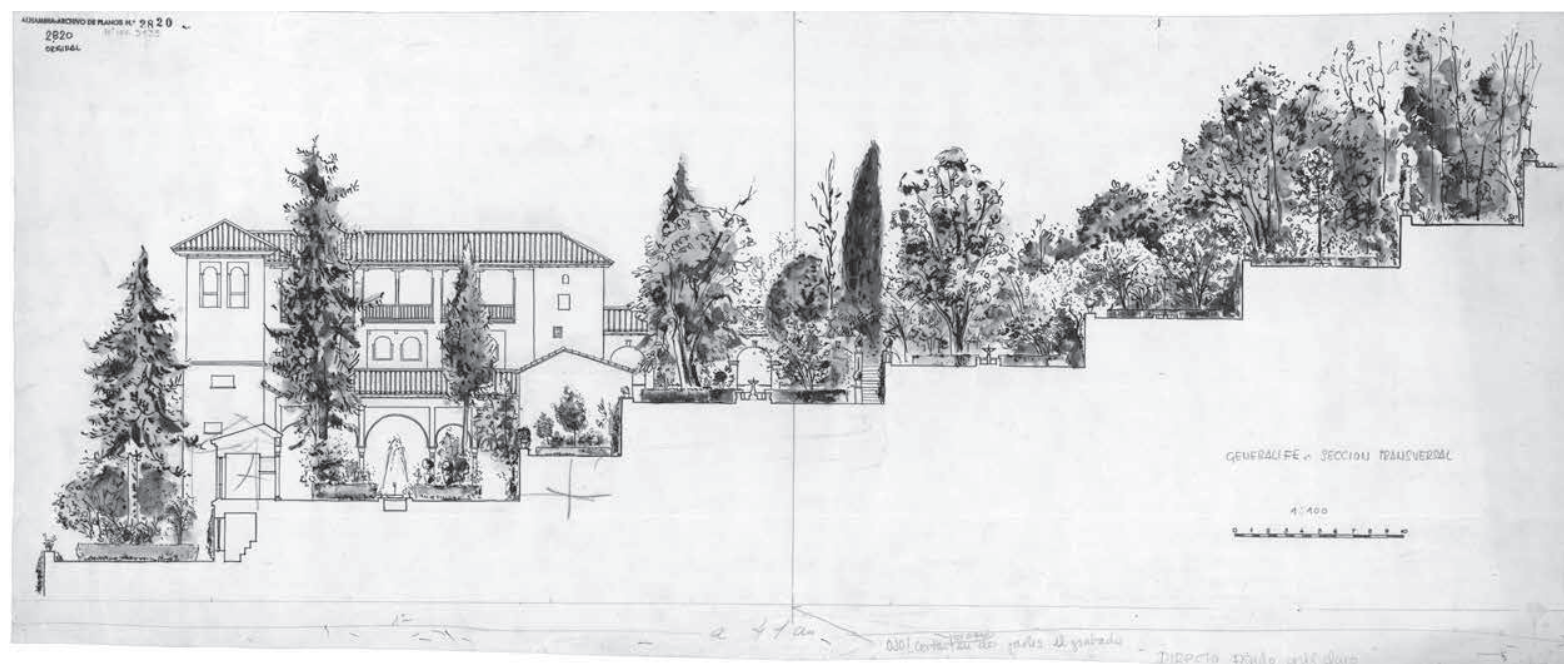

transformación que ha permitido conservar la función del sistema de bancales, estanques y acequias, pues nunca dejaron de ser elementos útiles para el riego de los cultivos, las terrazas y los jardines. En este lugar, incluso las fuentes y los saltadores de reconocido valor ornamental, construidas a lo largo de varios siglos, se enmarcaron dentro de una lógica constructiva que dotaba a la distribución del agua de una prioridad agraria, devolviendo siempre el sobrante a las acequias y evitando así cualquier despilfarro de este líquido preciado para la cultura islámica ${ }^{19}$.

Estas transferencias pueden ser interpretadas como una consecuencia lógica de un proceso de transformación en el cual se elige el camino más corto, aquel que conlleva una mínima energía para convertir las formas agrícolas en formas arquitectónicas ${ }^{20}$ y urbanas. En las técnicas de diseño de jardines parece mantenerse una cierta continuidad a lo largo del tiempo, aunque el modo de entender el arte y el paisaje ha podido bloquear este tipo de intercambios. John Dixon, por ejemplo, nos recuerda lo sucedido cuando la teoría del jardín trató de argumentar que sus esquemas procedían de la pintura, suprimiendo las continuidades entre las prácticas agrícolas y horticulturales ${ }^{21}$

En la actualidad, el paisajismo intenta recuperar algunas de estas relaciones perdidas entre los paisajes de cultivo y el diseño de los espacios libres a través de la agricultura urbana como fundamento para la producción de continuidades ecológicas y culturales. Desde la arquitectura, en cambio, sobre todo en ámbitos urbanos, esta cuestión sigue siendo una tarea pendiente, pues requiere de una ampliación de la noción de patrimonio capaz de asimilar los elementos y huellas agrícolas de los suelos comunes, no protegidos, como instrumento para la transformación territorial 22 .

Es posible encontrar diversos ejemplos de préstamo material y constructivo entre los bancales y el entorno, a veces animados por necesidades económicas o por

19. Ídem.

20. En España se conservan numerosos testimonios de patrimonio inmueble y etnológico construido con la misma lógica que se construyen los bancales, en contigüidad con ellos, como puede verse en el uso de la piedra seca en Cataluña y Aragón, en el medio rural de Sierra Mágina, en Jaén, en la Sierra de Enguera, Valencia, o en Menorca. Sin argamasa o conglomerante, se trata de una técnica fundamentada en una economía de subsistencia que aprovecha la proximidad de los recursos locales, como la reutilización del despedregado de los campos de cultivo o pasto que se acumulan en los márgenes. Hormas, chozos, eras y casetas, algunas procedentes del siglo XVIII, normalmente son espacios auxiliares de pastores y se confunden con las terrazas y los elementos de delimitación de terrenos. ESCOBEDO MOLINOS, Enrique. Los chozos de piedra. En: Jaén, pueblos y ciudades. Jaén: Diario Jaén, 1997-2000, p. 2095.

21. DIXON HUNT, John, op. cit. supra, nota 8, p. 85.

22. Un antecedente de esta sensibilidad hacia los bancales como un patrimonio a recuperar en el seno de la ciudad lo encontramos en The civic Survey of Edinburgh, de Patrick Geddes. Véase CASTELLANO PULIDO, Francisco Javier. Infraestructura y memoria: de las terrazas agrícolas de Geddes a los paisajes superpuestos de Beigel. En: Proyecto, Progreso, Arquitectura. Arquitectura e infraestructura. Sevilla: Editorial Universidad de Sevilla, noviembre de 2015, n. ${ }^{\circ}$ 15, pp. 74-89. ISSN 2171-6897. 
7. Perspectiva descompuesta del Generalife. Transferencias formales y funcionales desde el sistema agrícola de bancales, estanques y acequias preexistentes hacia la arquitectura residencial nazarí.

B) MODIFICACIÓN DE LA HIPÓTESIS DE CARLOS VILCHEZ SOBRE DIBUJO DE R. CABRERA ORTI. IALBERCA DEL PATIO DEL CIPRÉS DE LA SULTANA EN LUGAR DE LOS BAÑOS!

A) SECCIÓN DEL ESTADO ACTUAL DEL CONJUN TO ARQUITECTÓNICO DEL GENERALIFE SOBRE EL SISTEMA DE ACEQUIAS.

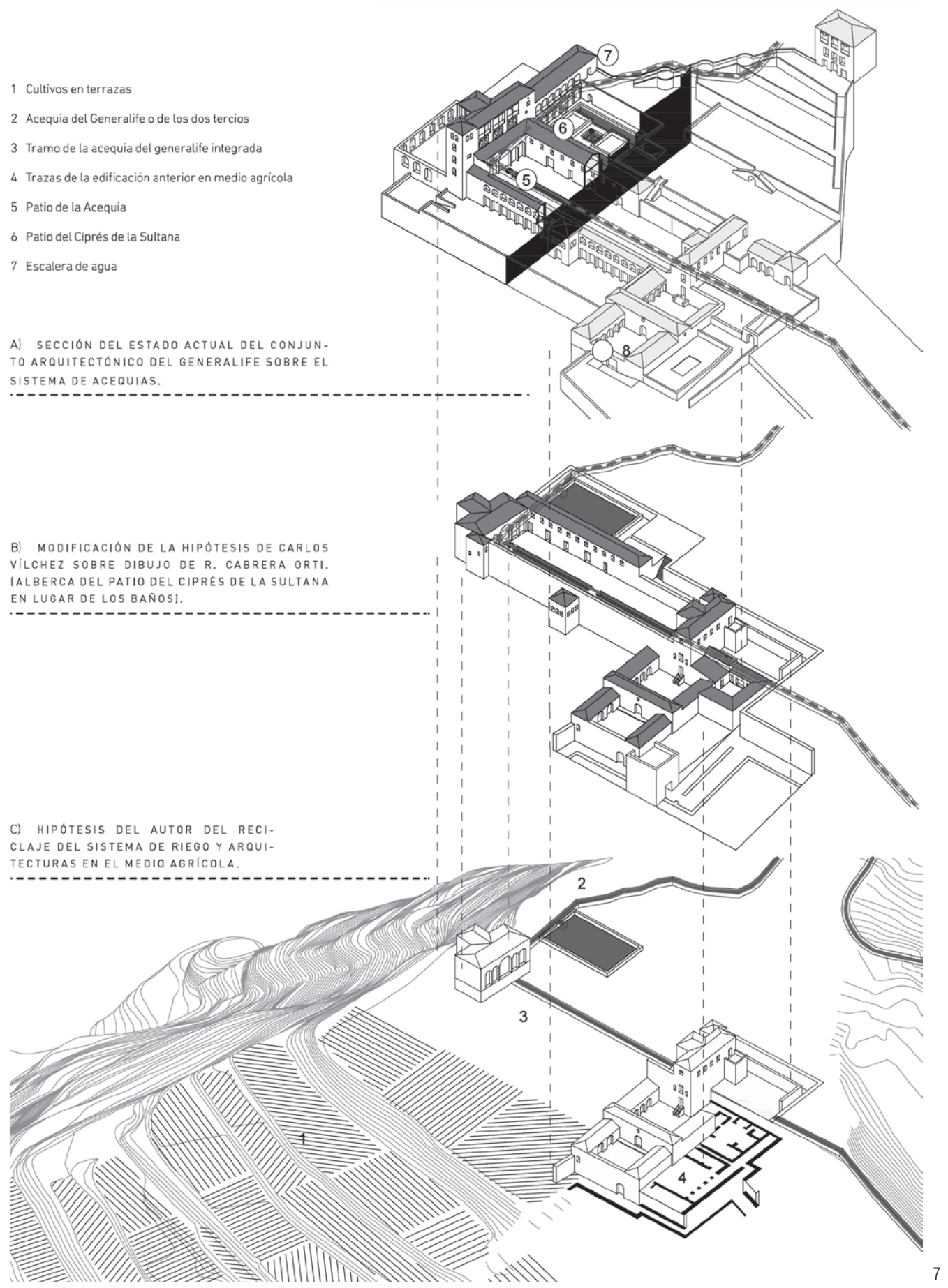


inspiraciones regionalistas, pero la consideración de las transferencias como un conjunto de cualidades también topográficas, geométricas y paisajísticas constituye, hasta la primera mitad del siglo XX, una estrategia marginal ${ }^{23}$.

Es a partir de la década de 1960 cuando algunos arquitectos volvieron la mirada hacia los paisajes anónimos construidos por los agricultores locales, especialmente los paisajes de bancales, procurando desentrañar algunas de las claves que configuran aquel territorio fértil para utilizarlas como argumento en su nueva arquitectura.

\section{EL BANCAL EXCAVADO Y LA MEMORIA DEL PAISAJE VOLCÁNICO EN EL MIRADOR DEL RÍO, DE CÉSAR MANRIQUE}

En el libro Lanzarote, arquitectura inédita (1974), el artista multifacético César Manrique quiso expresar los valores de la arquitectura vernácula lanzaroteña y el modo en que sus pobladores habían sabido aprovechar los recursos existentes desde la economía de medios ${ }^{24}$. Las viviendas y edificaciones agrícolas realizadas con la combinación de volúmenes prismáticos y paredes encaladas se organizaban según una forma de crecimiento orgánica donde dominaba la horizontalidad y se disponían en claro contraste con el material lávico de la isla ${ }^{25}$. Más allá de estas edificaciones, Manrique admiraba cómo la capacidad de experimentación de la población local con el material producido por las erupciones volcánicas, como los bolos, las piedras y el picón, había llevado a la creación de una peculiar cultura agraria capaz de transformar el paisaje con el objetivo de mejorar la fertilidad de la tierra ${ }^{26}$.

En este sentido, fueron la necesidad de captar el agua debido a la climatología subárida de Lanzarote, y de mejorar la protección contra los vientos alisios, que dificultaban el crecimiento de plantaciones como la vid, los principales motores para la ideación de una gran diversidad de infraestructuras que se erigieron en verdaderas arquitecturas del paisaje isleño. La multiplicación de los aljibes, tanto en terreno rural como en los núcleos de población, y la construcción de gavias, enarenados y gerias por el territorio fascinó a un conjunto de arquitectos y artistas entre los que se encontraba César Manrique ${ }^{27}$.

Resulta interesante la importancia que confería el arquitecto y artista en su obra a la memoria del paisaje agrícola construido por los campesinos en colaboración con las fuerzas de la naturaleza. Admiraba cómo las construcciones humildes se adecuaban de forma delicada a su contexto y su digno modo de envejecer, convirtiéndose en "fiel testimonio del paso del tiempo"28.

23. Véase el ejemplo de la casa Rumeu, construida completamente con piedra de Cadaqués, como la utilizada para hacer el muro de contención de la casa Julià. Estos muros de piedra autóctona, menos costosos que los cerramientos de ladrillo, establecían, a pesar de la geometría hexagonal de la casa, un motivo paisajístico vinculado al contexto rural, utilizando la misma piedra que en los bancales del exterior. En su interior se diseñaron muebles de obra aprovechando Ios desniveles, transfiriendo la misma lógica de las terrazas agrícolas existentes. LLOBET RIBEIRO, Xavier. Casa Rumeu. En: Docomomo Ibérico. Documentation and Conservation of the Architecture and Urbanism of the Modern Movement [en línea]. Fundación Docomomo Ibérico [consulta: 16-12-2018]. Disponible en: http://www.docomomoiberico.com/. Véase el proyecto publicado en CORREA, Federico; MILA, Alfonso. Casa Rumeu. En: Cuadernos de Arquitectura. Viviendas unifamiliares. Barcelona: Colegio Oficial de Arquitectos de Catalunya y Baleares, $2 .{ }^{\circ}$ trimestre de 1964, n. ${ }^{0}$ 56, pp. 15-17. ISSN 0011-2364.

24. MANRIQUE, César, et al. Lanzarote, arquitectura inédita: geología y paisaje, vivienda popular, arquitectura religiosa, arquitectura militar, chimeneas, puertas y ventanas, molinos. Arrecife, Lanzarote: Cabildo Insular, Servicio de Publicaciones, 1988. Edición original, 1974.

25. DÍAZ HERNÁNDEZ, Ramón; DOMÍNGUEZ MÚJICA, Josefina; PARREÑO CASTELLANO, Juan Manuel. La utopía de Manrique: el paisaje reinventado y la apropiación turística. En: Nuria BENACH, Miriam Hermi ZAAR, Magno VASCONCELOS P. JUNIOR, eds. Actas del XIV Coloquio Internacional de Geocrítica. Las utopías y la construcción de la sociedad del futuro. Barcelona, 2-7 de mayo de 2016 [en línea]. Barcelona: Universidad de Barcelona, 2016 [consulta: 10-01-2019]. ISBN 978-84-617-5447-2. Disponible en: http://www.ub.edu/geocrit/xiv_diazdominguez.pdf

26. Manrique asistió a la exposición "Architecture without architects", organizada en 1964 en el Museo de Arte Moderno de Nueva York. En ella aparecía el paisaje de La Geria de Lanzarote, influyendo decisivamente en sus decisiones posteriores. SABATÉ, Fernando; SABATÉ, Joaquín; ZAMORA, Antonio. César Manrique: la conciencia del paisaje. En: Joaquim SABATÉ, José FARRUJIA, coords. César Manrique: la conciencia del paisaje. Santa Cruz de Tenerife: Fundación Cajacanarias, 2013, p. 31.

27. Resulta de interés la serie de proyectos que se desarrollaron a partir del viaje realizado en 1963 junto a su amigo arquitecto Fernando Higueras, otro de los referentes de la apropiación de las estrategias de construcción del paisaje agrícola de Lanzarote como referencia de su arquitectura. ARCARAZ PUNTONET, Jon, op. cit. supra, nota 3, p. 91.

28. DÍAZ HERNÁNDEZ, Ramón et al., op. cit. supra, nota 24. 
8. Bancales del Mirador del Río en Lanzarote, César Manrique (1971 y 1973). Acceso sur.

9. Ventanal de vidrio en la ladera norte del Mirador del Río en Lanzarote, César Manrique.

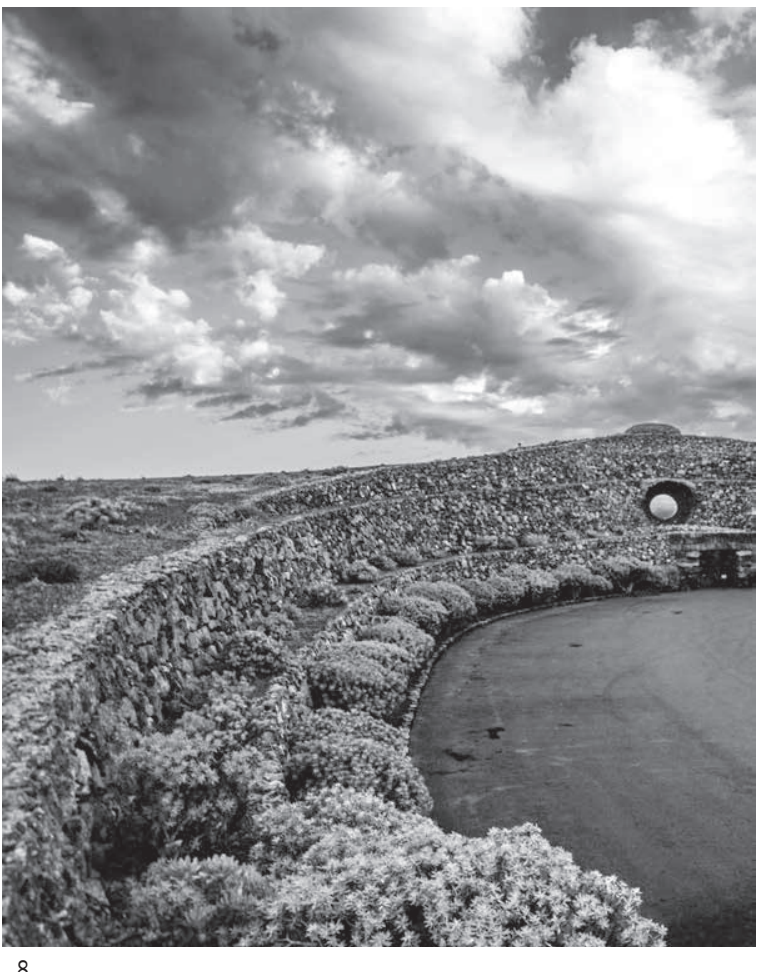

Trataba, a través de sus estudios sobre el paisaje y la arquitectura de Lanzarote, de aprehender algo de aquella organicidad tectónica de la vivienda isleña al tiempo que investigaba en el aspecto estereotómico del hábitat troglodita, que sabía aprovechar la porosidad del suelo volcánico.

A 479 metros sobre el nivel del mar, en el risco de Famara, César Manrique realizó, junto a los arquitectos Jesús Soto y Eduardo Cáceres, un ejemplo singular de arquitectura subterránea capaz de sintetizar en un solo emplazamiento muchas de las estrategias que había observado en Lanzarote. El Mirador del Río, realizado entre 1971 y 1973, le permitió transformar de forma delicada un lugar marcado por la preexistencia de una antigua batería militar para conformar un restaurantemirador abancalado y orientado a dos posiciones contrapuestas.

La dualidad que se establece en el proyecto, ocultando inicialmente las vistas panorámicas al visitante hasta su ingreso en el edificio, responde a la posibilidad de intensificar la experiencia de la posición privilegiada del lugar: desde la visión del volcán de La Corona en el sur hasta la amplia perspectiva que se abre cuando se transita por el interior del edificio hacia el norte, permitiendo divisar la franja costera del acantilado, el archipiélago Chinijo y el mar de fondo (figura 9). La arquitectura, de este modo, desaparece en una topografía artificial que actúa de plataforma de observación de los paisajes lejanos al tiempo que permite contemplar, y esto es lo más significativo, su noción del tiempo y de la historia del territorio de la isla. En la fachada sur, donde se ubica el acceso principal en posición centrada, se aplica la estrategia de rehundir levemente algunas zonas, colmatar y allanar el terreno existente, disponiendo terrazas curvas labradas en mollero de piedra ${ }^{29}$ de forma escaIonada que protegen la zona de entrada al conjunto del viento de los alisios. Estas terrazas evocan así los bancales agrícolas existentes en algunas zonas de la isla, como en el valle de Temisa, en Teguise o en el barranco del Palomo.

La disposición de dos huecos centrados, uno de ellos de forma adintelada, que permite el acceso al recinto desde el bancal inferior, y otro circular, situado en la segunda terraza, condensan dos referencias más de la historia del paisaje isleño: el detalle pétreo de acceso del taro prehispánico ${ }^{30}$ y los espacios subterráneos de cualidad escultórica que conoció Manrique en su trabajo

29. Como describe Francisco Galante, en los muros estratificados "fue necesario instalar unas vigas de madera con la suficiente inclinación para colocar sobre ellas una pared de piedra seca apoyada en una ligera capa de hormigón (...), en la monumental portada, al contrario, fueron colocadas grandes piezas de piedra, convenientemente numeradas tras su recogida para su definitiva instalación". GALANTE, Francisco; ALBORNOZ, Pedro. Mirador del Río. Teguise, Lanzarote: Fundación César Manrique, 2000, p. 55.

30. Ídem. Sobre este tipo de construcciones a menudo integrados con los bancales, de forma similar a los chozos de Sierra Mágina, véase también FARRAY BARRETO, J.; MONTELONGO FRÁNQUIZ, A. J. Refugios agrícolas, torres de vigilancia y taros en Lanzarote. En: $X$ Jornadas de Estudios sobre Lanzarote y Fuerteventura. Arrecife (Lanzarote): Servicio de Publicaciones de los Excmos. Cabildos Insulares de Lanzarote y Fuerteventura, 2004, p. 93 
con los jameos ${ }^{31}$, vinculados a la naturaleza del accidente geográfico.

Una vez en el interior, puede apreciarse cómo la arquitectura se resuelve también en este diálogo arte-naturaleza: en la planta inferior, una galería sinuosa rompe la conexión directa de las dos laderas del risco para dar paso a una gran sala conformada por dos espacios abovedados construidos como cuevas elipsoidales intersectadas en planta. La planta superior, también próxima a la idea de gruta, se abre al óculo que mira al paisaje volcánico y, en sentido ascendente, hacia la escalera helicoidal, que sirve de lucernario y emerge sobre la cima de la nueva topografía. Este elemento, como si se tratase de un extraño taro, es descompuesto en partes a través de una operación de abstracción posible gracias a la inclusión del vidrio, que parece seccionar el elemento dotándole de cierta ingravidez.

En el interior del espacio excavado, como en diversas obras de Manrique, domina el color blanco en contraste directo con la piedra volcánica del exterior, estableciendo una relación con la arquitectura vernácula lanzaroteña no en su forma, pero sí en los claroscuros reconocibles en el espacio doméstico tradicional. La extraña síntesis de estas referencias, junto a la conciencia del arte contemporáneo que había comenzado a desarrollar en Madrid y Nueva York, dota al proyecto de una clara singularidad en el panorama arquitectónico de la época.

El interés de César Manrique por el paisaje de bancales resulta evidente en su última gran intervención en Lanzarote, el Jardín de Cactus (1991) —un cactarium construido en una antigua cantera de picón o arena volcánica de Guatiza-, donde conformó una suerte de anfiteatro aterrazado de cultivos, pero es en el Mirador del Río, realizado veinte años antes, donde se lleva a cabo el intercambio y trasvase de conceptos, materiales y sistemas constructivos más interesante entre la terraza de cultivo y la arquitectura. El resultado puede ser visto como una síntesis artística ecléctica de jardines y estructuras enterradas donde se acomodan formas orgánicas de resonancia modernista con el conocimiento que poseería

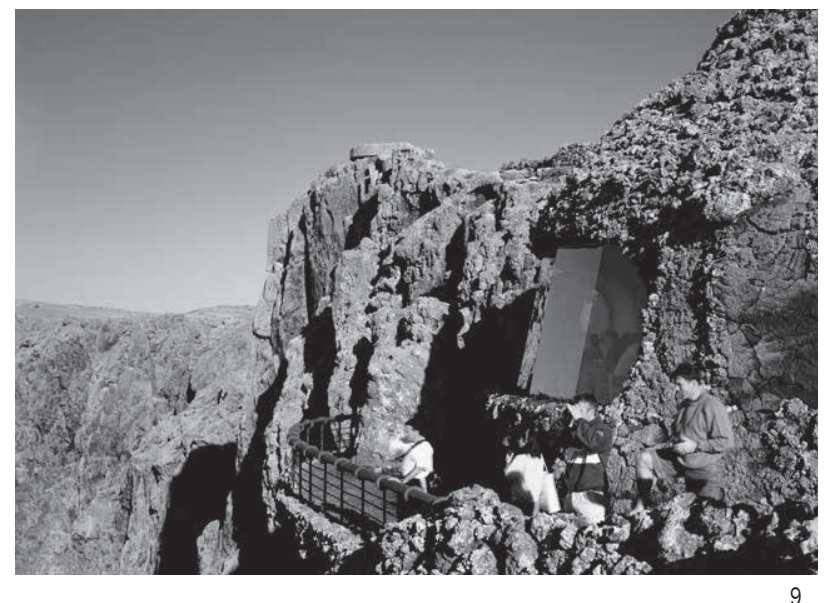

un agricultor y un geólogo sobre la lógica volcánica de la isla, conformando un nuevo paisaje arquitectónico subterráneo en su interior (figura 10).

A través del dibujo en sección puede apreciarse esta secuencia de realidades, a la derecha, las formas racionales de los bancales, construidos desde la experiencia vital de los campesinos. En el centro aparece el espacio excavado donde confluyen diversas referencias troglodíticas y a la izquierda, la realidad de la cima de la montaña cortada por un amplio ventanal que, en su contacto con el acantilado, produce un claro contraste con la piedra. Este proyecto constituye un conjunto orgánico difícil de clasificar, pues dialoga tanto con la memoria de las infraestructuras del paisaje agrícola como con la naturaleza alterada por los agentes geofísicos que caracterizan la geomorfología de la isla.

\section{LA ABSTRACCIÓN MATERIAL DE LAS TERRAZAS AGRÍCOLAS EN BAIÃO, MOLEDO Y SANTA MARÍA DO BOURO, DE EDUARDO SOUTO DE MOURA}

Souto de Moura es uno de los arquitectos que mejor representa en la actualidad la continuidad de los intercambios entre el bancal y la arquitectura. Un pequeño refugio de fin de semana situado en Baião, Portugal, construido 


\section{N21_PAISAJE DE BANCALES}

46

10. Secciones en sentido norte-sur del Mirador del Río. Levantamiento realizado en noviembre de 2007. 11. Casa en Baião, de Eduardo Souto de Moura (1990-1993).

12. Perspectiva descompuesta y en sección de la Casa en Baião.
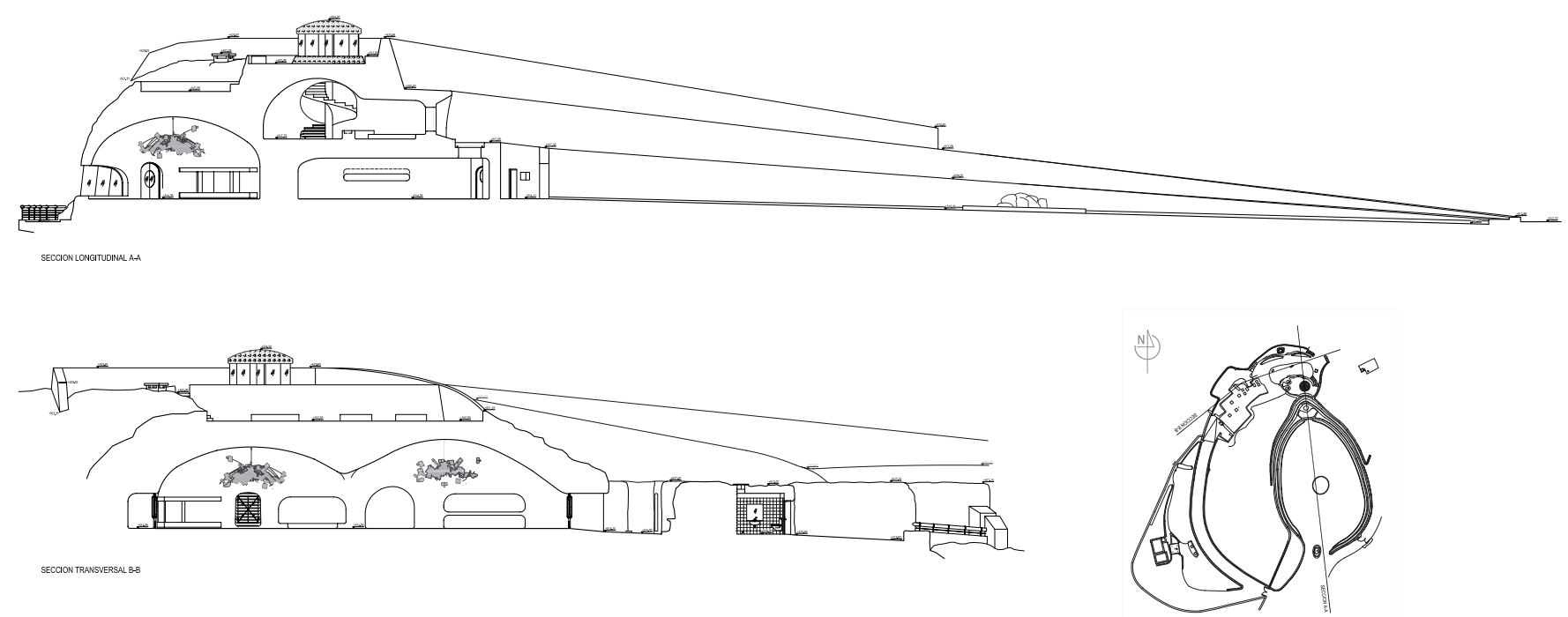

10

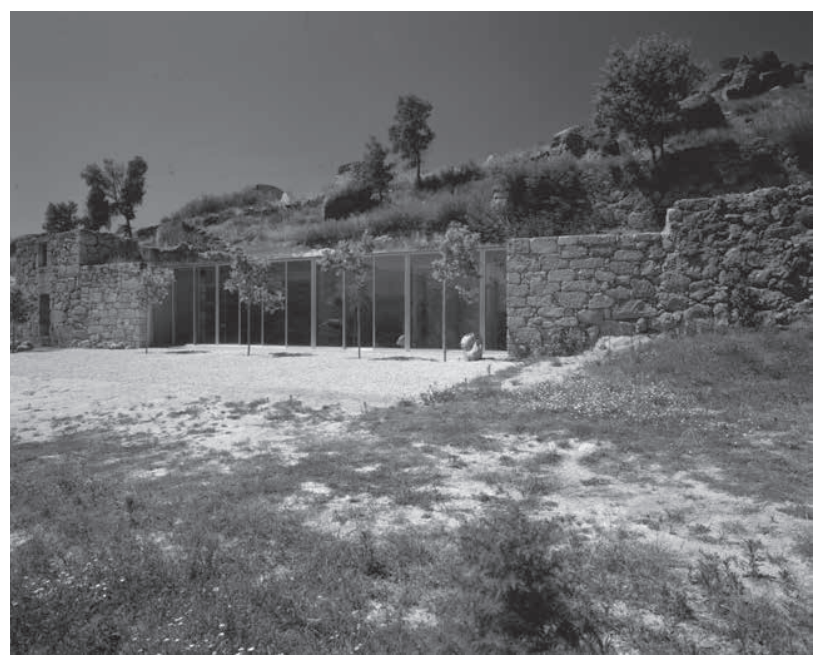

11

algunas de las transferencias que llevaría a cabo en el proyecto arquitectónico. Una edificación rural construida con sillares de granito portugués parece emparentarse con las terrazas agrícolas de la ladera por alinearse con ellas, utilizando también el mismo material, permaneciendo así en contigüidad física y constructiva con el territorio cultivado ${ }^{32}$. El desmonte de los sillares del muro de contención y el movimiento de tierras permitieron insertar la nueva vivienda, dejando la edificación en ruinas como un patio o jardín cercado que servía de vestíbulo.

Existe aquí una clara intención de conectar la memoria de la antigua casa rural en ruinas con la nueva edificación a través del recorrido de sus moradores, que transitan desde un recinto pétreo a un espacio construido de hormigón y camuflado en el entorno a través de una cubierta ajardinada.

El nuevo volumen insertado por Souto de Moura, de una sola planta y ciego por todos sus lados menos por el frente, dirige su mirada hacia el río Duero y al valle de Cerdeira, adoptando la orientación de los bancales existentes. El plano de vidrio refleja el paisaje circundante y el propio cielo, utilizando la capacidad de este material para, en cierta medida, desaparecer en su propio reflejo. En el interior, un fragmento de mampostería

32. BROTO, Carles; MINGUET; Josep Maria. Houses. Sant Adrià de Besòs: Instituto Monsa de Ediciones, 1996. 


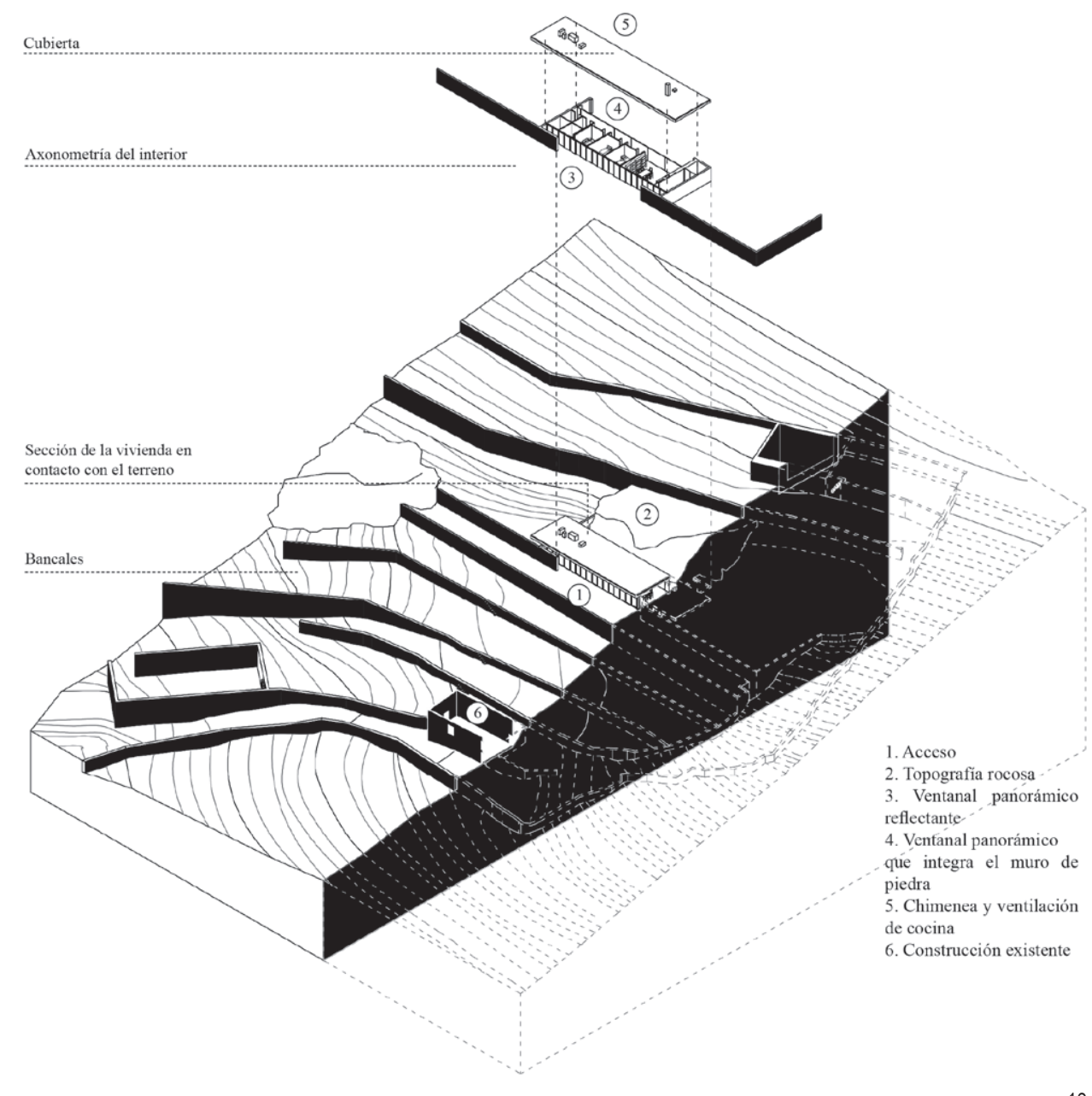

del antiguo bancal fue reutilizado para construir la chimenea, sirviendo de testigo material del proceso de transferencia elegido. Si la casa antigua en ruinas, de dos plantas de altura, parece una extensión en vertical del antiguo bancal, el refugio del arquitecto portugués prefiere considerarla como un fragmento abstracto de terraza agrícola, una arquitectura topográfica capaz de conservar, de algún modo, la libertad natural que ofrece el estado de abandono.

Una vivienda del mismo arquitecto, iniciada en 1991 en la localidad portuguesa de Moledo de Minho, ofrece una respuesta similar de integración en el paisaje de terrazas, pero esta vez seleccionando y depurando algunas de las transferencias ensayadas en las colinas de Baião. En este pequeño pueblo del municipio de Caminha, Souto de Moura se encontró con un terreno de bancales agrícolas de 1,5 metros, aproximadamente, sostenidos por muros de contención de piedra y con vistas hacia el océano Atlántico. El programa, algo mayor que en el existente en el refugio de Baião, se organiza también de forma perpendicular a una fachada acristalada que se alinea con los bancales. Fue la disposición original de estas terrazas, demasiado cercanas entre sí para construir la vivienda, lo que obligó a adoptar una estrategia nueva: la posibilidad de alterar la topografía con nuevos muros y plataformas (figura 12). Esta operación dilató el proceso durante varios años y terminó costando más que la propia vivienda. En palabras de Souto de Moura, el cliente, que, según el arquitecto portugués, era una persona inteligente, "estuvo de acuerdo con esta estrategia, y la casa fue ganando autonomía durante siete años, pasando de ser un rediseño a ser un diseño específico para este lugar y para estas personas; un lugar que fuimos descubriendo y modificando poco a poco"33. 
N21_PAISAJE DE BANCALES

48

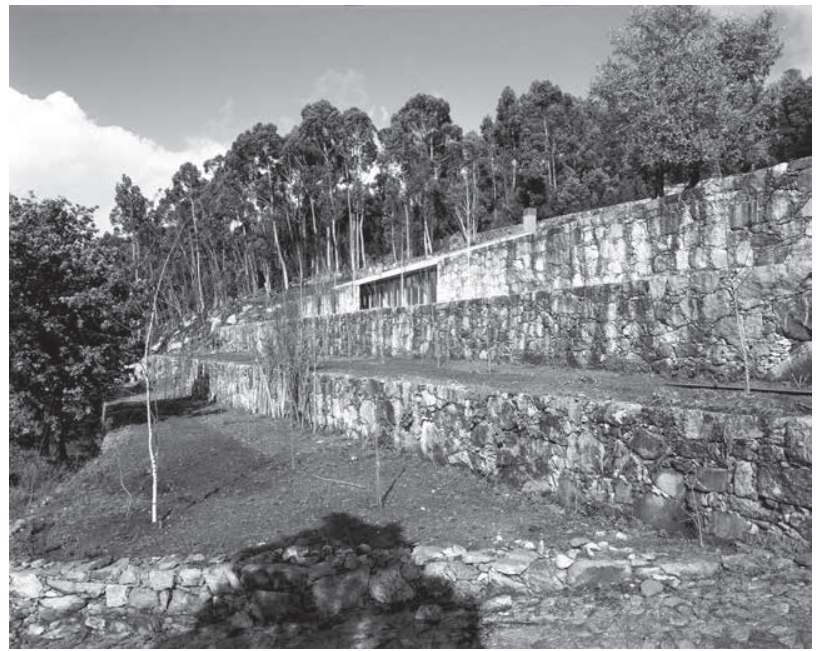

13

Resulta interesante la alteración de las prioridades del proyecto, capaz de concebir el paisaje de bancales como una parte fundamental de la arquitectura de la casa. Tanto los muros ciegos como el cerramiento que flanquea la cristalera de madera se construyeron con bloques irregulares de granito fijado en seco, sirviendo en el frontal como componente exterior de un cerramiento aislante. El alzado frontal de la vivienda permite concebirla como una oquedad vítrea realizada en un bancal de granito (figura 13), pero la cubierta adoptó una solución muy distinta a la adoptada en Baião. No se perseguía aquí el camuflaje del plano superior en el terreno vegetal, en palabras del propio autor: "La cubierta debería quedar a la vista, asumiéndose como un objeto nuevo, que se percibiría como un objeto caído del cielo"34. La losa, terminada con un pavimento de hormigón poroso, pudo acoger el sistema de recogida de aguas junto a los elementos de iluminación cenital y de ventilación realizados en acero inoxidable de un modo menos artificioso que en Baião. Se trata aquí de una operación de superposición "literal" de arquitecturas domésticas y agrícolas en el paisaje norteño portugués (figura 14).
13. Vista exterior de la Casa en Moledo, de Eduardo Souto de Moura (1991-1998).

14. Perspectiva descompuesta y en sección de la Casa en Baião.
Esta necesidad de distinción del plano de cubiertas, tratándose de un terreno reconfigurado, resulta coherente con la realización de una apertura trasera, una suerte de patio abierto a la ladera que desvela la existencia de un afloramiento de roca. Se refuerza así la presencia del material en el interior de la vivienda, conformando dos planos visuales de los que parece aproximarse y distanciarse a la vez desde el interior: la costa atlántica y la piedra del lugar $^{35}$. Esta operación de abstracción en el proceso de integración de la arquitectura sobre una terraza remodelada queda reforzada por los reflejos tanto del paisaje situado al frente de la casa como de la roca en la parte trasera.

Ambos proyectos de vivienda podrían quedar relacionados con la experiencia del propio arquitecto portugués con contextos con una fuerte impronta material, como es el caso de la posada en el Monasterio Santa María do Bouro (1989-1997). La inserción de una parte del programa en la base del edificio en ruinas, conformando un zócalo pétreo que se extiende en horizontal, parece dialogar con los bancales que descienden ladera abajo y la materialidad del propio monasterio. El modo de abordar la noción de patrimonio por parte de este arquitecto trasciende a la distinción entre edificio y territorio, pues el tiempo es trabajado como un material de proyecto abierto a la interpretación. En el caso del proyecto para Santa María do Bouro, tanto la edificación como el paisaje próximo podrían ser considerados como materia prima de un patrimonio más amplio que se encuentra en continua construcción. En palabras de Souto de Moura:

"Enfrentados ante dos caminos a seguir, optamos por rechazar la condición pura y simple de las ruinas en beneficio de la contemplación, y preferimos introducir materiales, usos, formas y funciones nuevas entre les choses, tal y como dijo Le Corbusier. El 'pintoresquismo' es cuestión del destino y no parte de un proyecto o de un programa"36.

A finales del siglo XX y principios del siglo XXI es posible apreciar una multiplicación del traslado de las cualidades materiales y formales de las estructuras y sistemas agrícolas preexistentes a la arquitectura rural y urbana, animados

34. Ídem.

35. SCHITTICH, Christian; RÜDIGER Krisch. In Detail: Single Family Houses. Basilea-Boston-Berlín: Birkhäuser, 2005, p. 148.

36. SOUTO DE MOURA, Eduardo. Rehabilitación para Pousada del Monasterio Cisterciense de Santa María do Bouro. En: El Croquis, 2005, n. ${ }^{\circ} 124$, p. 28. 


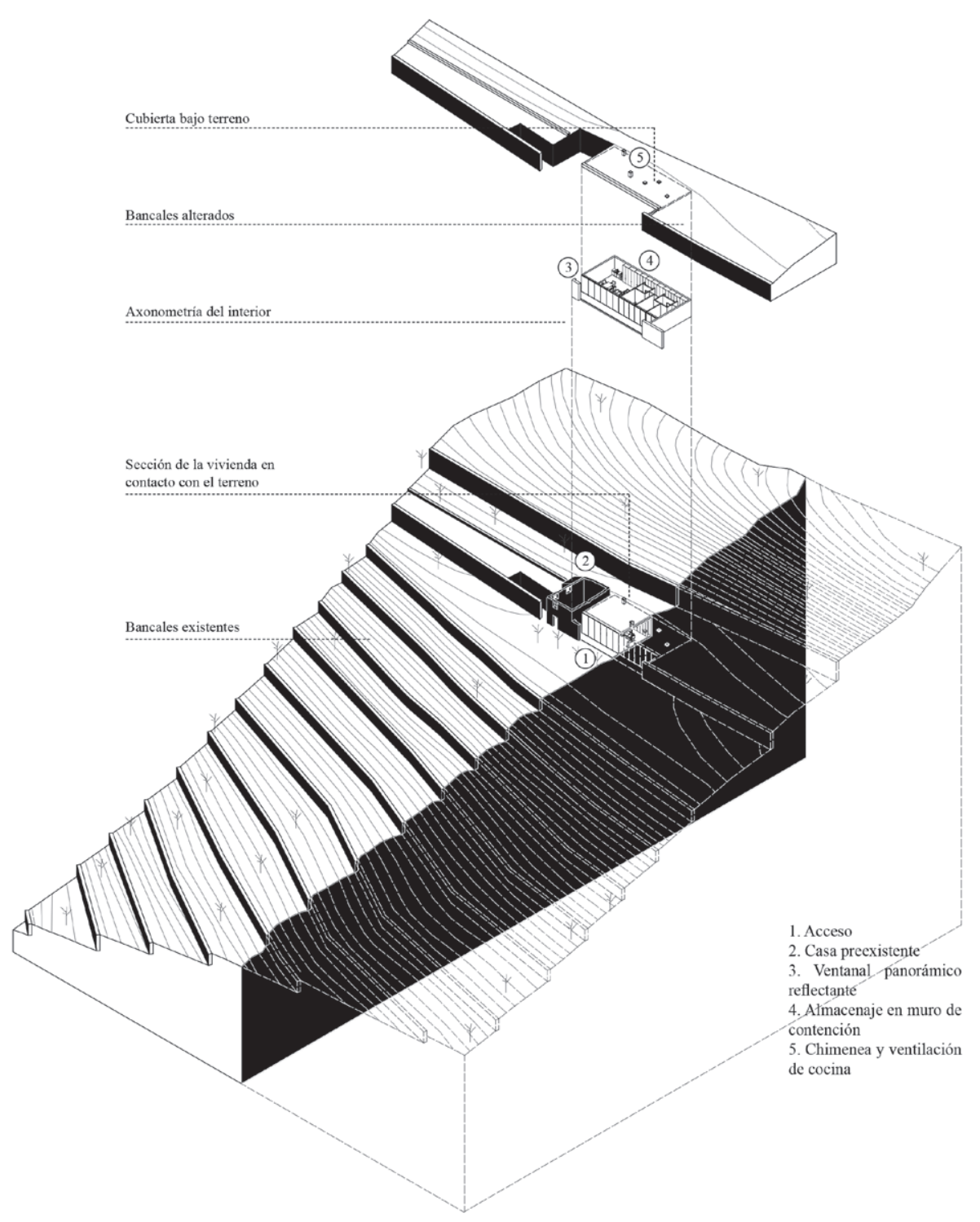

por una preocupación creciente por las cuestiones relacionadas con el paisaje y la creciente conciencia ecológica ${ }^{37}$. Las superficies de la arquitectura actual amplían cada vez más las aspiraciones de continuidad perdidas en la arquitectura moderna, ofreciendo las cualidades de la tierra y la vegetación para inscribirse en el terreno o para regular la temperatura de las edificaciones. El transvase energético parece ir acompañado de un constante intercambio conceptual, material y formal que aproxima muros y bancales, bajantes y canales de riego, cubiertas y suelos en cultivo, como había sucedido de forma espontánea en la ciudad excavada de Matera, en los bancales pétreos incas del Machu Picchu o en la terraza irrigada del Generalife, siglos atrás. Estos ejemplos son testimonio de la lógica de un proceso de transformación que no distingue entre disciplinas, que diluye los límites entre paisaje y arquitectura.

El interés desarrollado por la arquitectura contemporánea por integrar las obras humanas en el medio rural

37. Véase, por ejemplo, OAB+ADI Arquitectura. Construir sin destruir, casa BF. En: TC Cuadernos [en línea]. Valencia: General de Ediciones de Arquitectura, diciembre de 2016 [consulta: 10-01-2019]. Disponible en: https://www.tccuadernos.com/blog/construir-sin-destruir-casa-bf/. Véase también SCHULZDORNBURG, Julia. Casa Bancal. En: HIC arquitectura, marzo de 2013 [en línea] [consulta: 10-01-2019]. Disponible en: http://hicarquitectura.com/2013/03/ julia-schulz-dornburg-casa-bancal/ 
15. Vista exterior de la posada en Santa María do Bouro (1989-1997), de Eduardo Souto de Moura, con los bancales en primer plano.

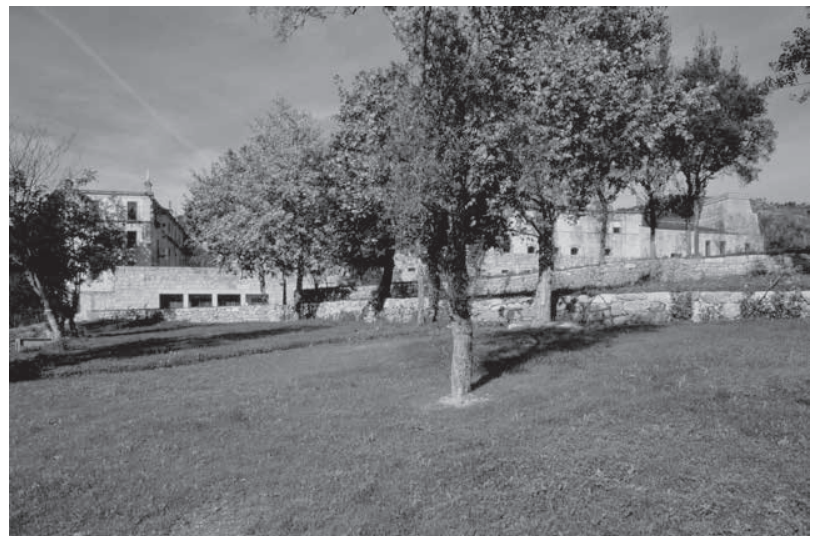

15

y natural, sobre todo desde las últimas décadas del siglo XX, parece llevar también a una cierta admiración sobre la capacidad cohesiva y adaptativa de la arquitectura tradicional. Se propone la recuperación de algunos de los préstamos conceptuales y materiales que, de forma espontánea, ayudaron a conformar conjuntos hoy reconocidos como patrimonio mundial. Con una conciencia crítica muy distinta, ya fuese desde el pensamiento orgánico o desde una racionalidad y sinceridad material, César Manrique y Souto de Moura se alimentaron de la experiencia de los constructores anónimos del paisaje de bancales en entornos rurales y desarrollaron estrategias capaces de renovar la arquitectura de su tiempo. La utilización de los planos abstractos e ingrávidos de vidrio, en contraste con el uso de materiales locales como la piedra y la madera, ayudados por el cemento o el hormigón armado, les permitía liberar el territorio enterrado bajo el bancal de su oscuridad natural para abrirlo hacia el paisaje que se situaba frente a ellos. El cuidado que se percibe en las obras de ambos arquitectos hacia el modo en el que envejecen los materiales no puede desligarse de su interés por el trabajo con el tiempo y la memoria, el respeto hacia las edificaciones e infraestructuras preexistentes como elementos depositarios de un patrimonio material, pero también intangible que, lejos de ser paralizado en el tiempo, puede ser renovado en cada intervención. $\square$

\section{Bibliografía citada}

ARCARAZ PUNTONET, Jon. La construcción del paisaje. Plan Parcial de Urbanización de Lanzarote. 1963. En: ZARCH: Journal of interdisciplinary studies in Architecture and Urbanism, 2016, n. 7. ISSN 2341-0531.

BROTO, Carles; MINGUET; Josep Maria. Houses. Sant Adrià de Besòs: Instituto Monsa de Ediciones, 1996.

CANIGGIA, Gianfranco; GIAN LUIGI, Maffei. Tipología de la edificación: estructura del espacio antrópico. Madrid: Celeste Ediciones, 1979 , p. 24.

CASTELLANO PULIDO, Francisco Javier. Infraestructura y memoria: de las terrazas agrícolas de Geddes a los paisajes superpuestos de Beigel = Infrastructure and memory: from Geddes agricultural terraces to Beigel's overlapping landscapes. En: Proyecto, Progreso, Arquitectura. Arquitectura e infraestructura. Sevilla: Editorial Universidad de Sevilla, noviembre de 2015, n. 15, pp. 74-89. ISSN 2171-6897.

CASTELLANO PULIDO, Francisco Javier. El patrimonio fértil. Transferencias entre el paisaje agrario y la arquitectura en los crecimientos urbanos. Director: Juan Domingo Santos. Tesis doctoral. Universidad de Granada. Departamento de Expresión Gráfica Arquitectónica y en la Ingeniería, 2015. http://hdl.handle.net/10481/41119

CORREA, Federico; MILA, Alfonso. Casa Rumeu. En: Cuadernos de Arquitectura. Viviendas unifamiliares. Barcelona: Colegio Oficial de Arquitectos de Catalunya y Baleares, $2 .^{\circ}$ trimestre de 1964, n. ${ }^{0}$ 56, pp. 15-17. ISSN 0011-2364.

DÍAZ HERNÁNDEZ, Ramón; DOMÍNGUEZ MúJICA, Josefina; PARREÑo CASTELLANO, Juan Manuel. En: Nuria BENACH, Miriam Hermi ZAAR, Magno VASCONCELOS P. JUNIOR, eds. Actas del XIV Coloquio Internacional de Geocrítica. Las utopías y la construcción de la sociedad del futuro. Barcelona, 2-7 de mayo de 2016 [en línea]. Barcelona: Universidad de Barcelona, 2016 [consulta: 10-01-2019]. ISBN 978-84-617-5447-2. Disponible en: http://www.ub.edu/geocrit/xiv_diazdominguez.pdf

DIXON HUNT, John. Greater perfections: the practice of garden theory. Londres: Thames \& Hudson, 2000.

ESCOBEDO MOLINOS, Enrique. Los chozos de piedra. En: Jaén, pueblos y ciudades. Jaén: Diario Jaén, 1997-2000. 
PROYECTO, PROGRESO, ARQUITECTURA

51

FARRAY BARRETO, J.; MONTELONGO FRÁNQUIZ, A. J. Refugios agrícolas, torres de vigilancia y taros en Lanzarote. En: X Jornadas de Estudios sobre Lanzarote y Fuerteventura. Arrecife (Lanzarote): Servicio de Publicaciones de los Excmos. Cabildos Insulares de Lanzarote y Fuerteventura, 2004

GALANTE, Francisco; ALBORNOZ, Pedro. Mirador del Río. Teguise, Lanzarote: Fundación César Manrique, 2000.

HYSLOP, John. Inka settlement planning. Austin: University of Texas Press, 1990.

KAUFFMANN DOIG, Federico. Historia y arte del Perú antiguo. Lima: Ediciones Peisa-La República-Gloria, 2002.

LAUREANO, Pietro. Atlas de agua: Ios conocimientos generales para combatir la desertificación. Barcelona: Laia, 2005.

LLOBET RIBEIRO, Xavier. Casa Rumeu. En: Docomomo Ibérico. Documentation and Conservation of the Architecture and Urbanism of the Modern Movement [en línea]. Fundación Docomomo Ibérico [consulta: 16-12-2018]. Disponible en: http://www.docomomoiberico.com/

MADERUELO, Javier. Jameos del Agua. Lanzarote: Fundación César Manrique. 2006.

MANRIQUE, César, et al. Lanzarote, arquitectura inédita: geología y paisaje, vivienda popular, arquitectura religiosa, arquitectura militar, chimeneas, puertas y ventanas, molinos. Arrecife, Lanzarote: Cabildo Insular, Servicio de Publicaciones, 1988. Edición original, 1974

MÚJICA, Elías. Andenes. Arquitectura productiva inca. En: Revista Arkinka. Lima: Arkinka, 1996, n. ${ }^{\circ}$ 3, ISSN 1815-9273.

MURATORI, S. Civiltà e territorio. Roma: Centro Studi di Storia Urbanistica, 1967.

NILES, Susan A. Style and function in inca agricultural works near Cuzco. En: Ñawpa Pacha: Journal of Andean Archaeology, 1982, n. ${ }^{\circ} 20$, pp. 163182. ISSN 0077-6297.

OAB+ADI Arquitectura. Construir sin destruir, casa BF. En: TC Cuadernos [en línea]. Valencia: General de Ediciones de Arquitectura, diciembre de 2016 [consulta: 10-01-2019]. Disponible en: https://www.tccuadernos.com/blog/construir-sin-destruir-casa-bf/.

ORIHUELA UZAL, Antonio; RODRÍGUEZ MORENO, Miguel. Casas y palacios nazaries: siglos XIII-XV. Sevilla: Junta de Andalucía, Consejería de Cultura, Consejería de Turismo y Deporte; Granada: El Legado Andalusí; Barcelona: Lunwerg Editores, 1996.

SABATÉ, Fernando; SABATÉ, Joaquín; ZAMORA, Antonio. César Manrique: la conciencia del paisaje. En: Joaquim SABATÉ, José FARRUJIA, coords. César Manrique: la conciencia del paisaje. Santa Cruz de Tenerife: Fundación Cajacanarias, 2013.

SCHITTICH, Christian; RÜDIGER Krisch. In Detail: Single Family Houses. Basilea-Boston-Berlín: Birkhäuser, 2005.

SOUTO DE MOURA, Eduardo. Casa en Moledo. En: El Croquis. Eduardo Souto de Moura 1995-2005. La naturalidad de las cosas. 2005, n. ${ }^{\circ} 124$, pp. 54-61. ISSN 0212-5633.

SOUTO DE MOURA, Eduardo. Rehabilitación para Pousada del Monasterio Cisterciense de Santa María do Bouro. En: El Croquis. Eduardo Souto de Moura 1995-2005. La naturalidad de las cosas. 2005, n. ${ }^{\circ} 124$, p. 28-43. ISSN 0212-5633.

SCHULZ-DORNBURG, Julia. Casa Bancal. En: HIC arquitectura, marzo de 2013 [en línea] [consulta: 10-1-2019]. Disponible en: http://hicarquitectura. com/2013/03/julia-schulz-dornburg-casa-bancal/

TITO ROJO, José; CASARES PORCEL, Manuel. El jardín hispanomusulmán: Ios jardines de al-Andalus y su herencia. Granada: Universidad de Granada, 2011.

TRILLO DE LEYVA, Juan Luis. Argumentos sobre la contigüidad en arquitectura. Sevilla: Universidad de Sevilla, 2001.

VÍLCHEZ VÍLCHEZ, Carlos. El Generalife. Granada: Proyecto Sur, 1991.

Francisco Javier Castellano Pulido (Granada, 1975). Doctor Arquitecto por la E.T.S. de Arquitectura de Granada (2015). Su tesis doctoral, "El patrimonio fértil, transferencias entre el paisaje agrícola y la arquitectura en los crecimientos urbanos", obtuvo el premio de la X Bienal Iberoamericana de Arquitectura y Urbanismo. Profesor Asociado de Proyectos Arquitectónicos en la E.T.S. de Arquitectura de la Universidad de Málaga desde 2010. Ha sido invitado como investigador en el Instituto del Patrimonio Turístico de la Universidad Central de Chile (2011-2012). Ha participado como investigador en Proyectos I+D financiados por Dirección General de Arquitectura y Vivienda de la C.0.P.T. de la Junta de Andalucía (invesigador principal en 2009-2011 y en 2005-2008). Actualmente compagina su labor docente con la actividad profesional en CUAC Arquitectura, estudio del que es co-fundador, seleccionado para el pabellón español de la Bienal de Arquitectura de Venecia (2008, 2016), la exposición Above MM en México-España (2014-2015), el Centro Andaluz de Arte Contemporáneo (Sevilla), Mostra Espanha en Portugal (Évora, 2015) y Architecture Set, en Shanghái (2015). Su estudio ha sido seleccionado por Rafael Moneo y Eduardo Souto de Moura para el IV Encuentro Luso-Español de Arquitectura y ha recibido también el reconocimiento a su trayectoria en el certamen Design Vanguard 2016 (Nueva York), siendo elegido como uno de los diez estudios emergentes con mayor proyección internacional. 
BANCALES HABITADOS: DE LA REUTILIZACIÓN EN LA ARQUITECTURA TRADICIONAL AL TRABAJO CON EL TIEMPO DE CÉSAR MANRIQUE Y SOUTO DE MOURA LIVING TERRACES: FROM REUSE IN TRADITIONAL ARCHITECTURE TO CÉSAR MANRIQUE AND SOUTO DE MOURA'S WORK WITH TIME

Francisco Javier Castellano Pulido (https://orcid.org/0000-0002-9287-1983)

p. 37 The organic growth processes of the pre-industrial city, according to research carried out in the 1970s by the Italian architect and professor Gianfranco Caniggia, allowed agricultural culture and its systems to form part of its processes of change, creating places with contents and dynamics open to the gradual transformations of the territory ${ }^{1}$. This author attributed it to what he called spontaneous awareness, defining it as "the capacity of an active subject to adapt, in its development, to the inherited cultural essence, without the need or obligation of mediations or decisions"2. Juan Luis Trillo pointed out something similar about tradition in architecture, product of a communal work in which some operators interpreted the general feeling, allowing "continuity in a double sense, in the temporal sequentiality of the architecture and in the synchronous homogeneity of the landscape"3. The continuity and homogeneity is related to what some authors call the cohesive quality of popular architecture, which can be applied both to the construction of the agricultural landscape and to architectural and urban development:

"Rural man lived in harmony with his landscape, adapting himself to the environment both in regard to his productive activity, agriculture, and in regard to his constructions for living. Caring for the land as sustenance and as a way of life was essential for the development of these communities. Therefore, consideration of the climate, topography and local materials was an intrinsic approach to traditional activity"4.

From the 1960s, thanks to a growing awareness of the degree of irreversibility that human actions can have on

p. 38 the environment, architects and artists adopted a new sensitivity towards the agricultural landscape, highlighting the uniqueness of the terraces. But this sensitivity, which we could describe as ecological and environmental, was not applied to the architectural design of most proposals, with a few exceptions ${ }^{5}$. Faced with the absence of spontaneous awareness, it seems necessary to acquire the critical awareness that Caniggia demanded for new architectural works. Thus, for contemporary projects it is useful to search for experiences from historical architecture in which there is some kind of exchange between the pre-existing agriculture of the place or its surroundings and the planned architectural programs. The cultivation terraces occupy a privileged place among these experiences for their ability to order the territory, improving the fertility of the land and making a mark on the landscape.

The architect Juan Luis Trillo puts us on this track in his essay Argumentos sobre la contigüidad en arquitectura ${ }^{6}$, a stimulating allegation about speculative activity that reopens the debate on the role of heritage in contemporary projects. His interest is directed towards the creative processes that lead to the transfer of qualities of some forms, matters or ideas to others, identifying approximation strategies that he calls minimum energy, also called economy of means or maximum internal economy law, which translates as "The choice of the shortest path between the resulting and initial forms and in the reuse of materials"7. According to this author, these conceptual operations - guided by contiguous relationships - can be extrapolated to any design activity and, above all, they seem to "reopen a broader field of operations, in relation to heritage assets". Beyond rigid concepts, it gives us a way to read the past that allows the articulation of continuity and discontinuity by attending to the processes and relationships that we are able to find between realities of different orders. In the case of the treatment of gardens, this is easy to affirm, since its development is based on enhanced agricultural procedures and images, that is, the transfer of concepts is perceived as natural:

"Clearings in a forest or a flowery meadowland became lawn and grass sward. (...) Ornamental canals in Dutch gardens were an aesthetic extension of drainage ditches in the low-lying polders (...) Terraces were derived from hillsides shaped for agriculture (...). In similar fashion, fountains and hydraulic systems grew out of irrigation needs and techniques, or the elaboration within gardens of allees and bosquets (groves) developed from the forester's management of woodland and hunting territory (...)" .

Material and formal transfers or loans between terraced landscapes and architecture, however, are not exclusive to the design of gardens, they are present in the shaping of architectures recognized for their integration in the environment, as can be seen in some of the most emblematic World Heritage Sites, such as the historic sanctuary of Machu Picchu, in Peru, La Alhambra and El Generalife, in Granada, and the Sassi of Matera in the Italian region of Basilicata, added by UNESCO in 1983, 1984 and 1993, respectively.

TRANSFERS AND EXCHANGES BETWEEN AGRICULTURAL TERRACES AND TRADITIONAL ARCHITECTURE: THE EXAMPLE OF MATERA, MACHU PICCHU AND EL GENERALIFE

The evolutionary process of the agricultural terraces of the Inca culture constitutes a paradigmatic case of transfer by constructive contiguity thanks to processes in which the reuse of materials and techniques led to the acquisition

p. 39 of a symbolic dimension of great relevance for the architecture. The terraces were horizontal platforms built with low stone retaining walls, constituting a highly productive system ${ }^{10}$. The constructive strategies derived from this system extended through the highlands, which required its adaptation to an increasingly complex topography. As they reached further uphill, the slope became more acute and the height of the walls of the agricultural platforms could acquire greater dimensions, transforming them into true architectural structures of urban scale and aspect (figure 1) 1$)^{11}$. 
In this upward movement, one of the different types of platforms or terraces built —-the so-called high prestige ${ }^{12}$ _ were so densified that they ceased to have real productive value, that is, the slope was so pronounced that the terraces became very narrow and the increase in the productive surface did not compensate for the effort to build them. The strong impression that these terraces made on the territory, on the other hand, allowed them to be used for representative purposes, facilitating their translation into the symbolic language of architecture ${ }^{13}$ (figures 2 and 3). The transfer of the construction techniques of the series appears here as a technical and formal displacement from the agricultural to the architectural of great importance for the Inca culture. In fact, agricultural terraces not only became the main form of architecture in the territory, but also became the most significant way of demonstrating human occupation.

The case of the Sassi of Matera, in the Italian region of Basilicata, as well as other settlements of the Murge plateau, is a unique example of urbanization that has allowed its growth and intensification over time without losing the original agropastoral matrix. Its overall arrangement responds both to the need to take advantage of water or energy and to the protection of the soil, an unavoidable part of the sustainability of the entire system ${ }^{14}$. In this way, different cultures were able to take advantage of the edges of narrow and deep gorges called gravines, with little incoming water, to create a prehistoric stone oasis with great expressiveness. As can be seen in figure 4 , the architecture is developed in a cohesive way with the water infrastructures, producing a physical synthesis capable of integrating troglodytic strategies for the capture of water with the construction of terraces that, thanks to reuse and recycling processes, have been able to form the basis of subsequent urban transformations. This constructive logic of minimal energy seems to have been maintained over time: if the material extracted from the rock excavation itself was used from prehistoric times in new constructions or to expand and cover the slopes, in the Middle Ages some processes of transformation allowed the conversion of hypogeal granaries into churches and silos or cisterns into homes. Some orchards are still conserved today - called garden-eras or hanging terraces - which serve as testimony to the interesting urban ecosystem that has been sustained over time thanks to the constant process of reuse and interpretation of its hydroagricultural matrix. In this process of cohesive growth, every urban form responds, in some way, to the possibility of more efficient transformation of the original irrigated landscape:

"The irrigated orchard and the pastures became meeting places for the extended family (...). The large community cistern that collects the water that falls from the roofs was excavated in the central courtyard. The roof is built inside p. 41 the walls, which means that not a single drop of rain is wasted, but led to the cistern through terracotta channels. The overlapping step becomes a hanging garden. The lateral drainage channels are transformed into stairs and vertical connections within the urban complex. The organization of the alleys derives from its adherence to the canal system..."15.

The monumental complex of El Generalife, in Granada, constitutes a paradigmatic case of transformation of a terraced agricultural landscape of medieval Islamic origin from pre-existing agricultural infrastructures. In this summer p. 42 residence of the sultan, located outside the walls of $L a A l h a m b r a$, the process of integration of agricultural terraces has as a unifying element: water. Similar to other allotments around the city, it is a farm that includes its own residence in the Mediterranean tradition that was used for production and leisure. The hillside on which it is situated, devoid of natural springs, needed a sophisticated irrigation system that would allow water to be carried to the Alhambra fortress, thereby raising the option of creating gardens and orchards. The Acequia Real [or Royal Waterway] can be considered one of the primary constructions for the terraced landscape that today we value for its high productivity and importance to our heritage $^{16}$. This Nasrid infrastructure takes its water from a tributary of the Darro River, six kilometers from the Alhambra, branching off in the Acequia del Tercio, which conducts water through an upper level to irrigate the higher agricultural areas, and the Acequia Dos Tercios, which runs below until returning to the main one. On the lower course is one of the buildings from the Palace of El Generalife, which feeds water into the main axis of its courtyard, the so-called Patio de la Acequia (figure 5) ${ }^{17}$.

In the evolution of El Generalife, it is possible to appreciate a certain respect for the layout and elements belonging to the old buildings and also to agricultural infrastructures (figure 7). The delicate assimilation by the Islamic architecture of the channels, ponds ${ }^{18}$ and walls of the pre-existing building and the agricultural terraces is visible, aligning the arrangement of the new constructions with the terraces and adopting the elongated proportions of the water infrastructure for the main patio. This central position allows the channel to provide a symbolic function of the pools also seen in other parts of La Alhambra. In the high gardens (figure 6) a progressive process of refinement can also be seen in the landscaping system that reaches the 15th century and extends the same logic of the irrigated terraces uphill, taking as a starting point some pre-existing orchards connected through the so called Escalera de agua [Water Ladder].

In the landscape arrangement formed by El Generalife, the transformation process that enabled the function of the terraced system, ponds and ditches, to be preserved is especially interesting, since they never ceased to be used p. 43 for the irrigation of crops, terraces and gardens. In this place, even the fountains and jets of recognized ornamental value, built over several centuries, were framed within a constructive logic that gave water distribution an agricultural 
priority, always returning the surplus to the ditches and thus avoiding any waste of this liquid that Islamic culture prized so highly ${ }^{19}$.

These transfers can be interpreted as a logical consequence of a transformation process of choosing the shortest path; the one that entails minimal energy to convert agricultural forms into architectural and urban forms ${ }^{20}$. In garden design techniques, certain continuity seems to be maintained over time, although the way of understanding art and landscape has been able to block this type of exchange. John Dixon, for example, reminds us of what happened when garden theory tried to argue that its designs came from painting, suppressing continuities between agricultural and horticultural practices ${ }^{21}$.

Nowadays, landscaping tries to recover some of these lost relationships between cultivated landscapes and the design of free spaces through urban agriculture as the basis for making ecological and cultural continuity. In architecture, on the other hand, especially in urban areas, this issue remains a pending task, since it requires the notion of heritage to become capable of assimilating agricultural elements and landmarks in common, unprotected soils as an instrument for territorial transformation ${ }^{22}$

It is possible to find several examples of material and constructive borrowing between the terraces and the

p. 45 environment, sometimes animated by economic needs or by enthusiastic regionalism, but the consideration of these transfers as an added set of topographic, geometric and landscape qualities was a marginal strategy until the first half of the twentieth century ${ }^{23}$.

It was in the 1960s when some architects turned their attention to the anonymous landscapes built by local farmers, especially the terraced landscapes, trying to tease out some of the keys of that fertile territory to use them as arguments in their new architecture.

\section{THE EXCAVATED TERRACE AND THE MEMORY OF THE VOLCANIC LANDSCAPE IN THE MIRADOR DEL RÍO BY CÉSAR MANRIQUE}

In the book Lanzarote, arquitectura inédita (1974), the multifaceted artist César Manrique wanted to express the values of Lanzarote's vernacular architecture and the way in which its inhabitants had taken advantage of the existing resources with economy of means ${ }^{24}$. The houses and agricultural buildings, made with the combination of prismatic volumes and whitewashed walls, were organized according to a form of organic growth dominated by horizontality and arranged in clear contrast with the island's lava ${ }^{25}$. Beyond these buildings, Manrique admired how the local population's capacity for experimenting with the material produced by volcanic eruptions, such as lava balls, stones and lapilli, had led to the creation of a peculiar agrarian culture capable of transforming the landscape with the aim of improving the fertility of the land ${ }^{26}$.

In this sense, the need to capture water due to the sub-arid climate of Lanzarote and to improve protection against trade winds, which hindered the growth of plantations such as the vine, were the main engines for the ideation of a great diversity of infrastructures that became true landscape architectures for the island. The multiplication of cisterns, both in rural land and in the population centers, and the construction of gavias, enarenados and gerias through the territory fascinated a group of architects and artists that included César Manrique ${ }^{27}$.

It is interesting to note the importance that the architect and artist gave in his work to the memory of the agricultural landscape built by the peasants in collaboration with the forces of nature. He admired how humble constructions adapted delicately to their context and their dignified way of aging, becoming "faithful testimony of the passage of

p. 46 time"28. He tried, through his studies on the landscape and architecture of Lanzarote, to apprehend some of the tectonic organicity of the island's dwellings while investigating the stereotomic aspect of the troglodyte habitat, which knew how to take advantage of the porosity of the volcanic soil.

At 479 meters above sea level, on the Famara cliff, César Manrique made, together with the architects Jesús Soto and Eduardo Cáceres, a unique example of underground architecture capable of synthesizing in a single location many of the strategies he had observed in Lanzarote. The Mirador del Río, carried out between 1971 and 1973, allowed him to delicately transform a place marked by the preexistence of an old gun battery to form a terraced lookout restaurant with views from two contrasting positions.

The duality established by the project, initially hiding the panoramic views from the visitor until they enter the building, responds to the possibility of intensifying the experience of the privileged position of the place: from the view of the volcano of La Corona, in the south, to the wide perspective that opens when traveling through the interior of the building to the north, offering views of coastal strip of the cliff, the Chinijo archipelago and the sea in the background (figure 9). The architecture, in this way, disappears in an artificial topography that acts as an observation platform for distant landscapes while allowing us to contemplate, and this is the most significant aspect, its notion of time and the history of the territory of the island. On the south façade, where the main access is placed in a central position, the strategy of slightly recessing some areas, filling and smoothing the existing land has been applied to create stepped curved terraces carved into the stone ${ }^{29}$ that protect the entrance area from the trade winds. These terraces thus evoke the existing agricultural terraces in some areas of the island, such as the Temisa valley, in Teguise or the Palomo ravine.

The arrangement of two centered cavities, one of them lintelled, allows access to the enclosed space from the lower terrace, and another circular one on the second terrace, condenses two more references to the history of the island's landscape: the stone details at the entrance of the prehispanic $\operatorname{tar}^{30}$ and the underground spaces of p. 47 sculptural quality that Manrique found in his work with the Jameos ${ }^{31}$, linked to the nature of the geographical feature. 
Once inside, one can see how the architecture is resolved in the same art-nature dialogue: on the lower floor, a sinuous gallery breaks the direct connection of the two slopes of the cliff to give way to a large room formed by two vaulted spaces built as intersected ellipsoidal caves. The upper floor, also close to the idea of a cave, opens to the oculus that overlooks at the volcanic landscape and, upwards, towards the spiral staircase, which serves as a skylight and emerges on the top of the new topography. This element, as if it were a strange taro, is broken down in parts through an operation of abstraction that is possible thanks to the inclusion of glass, which seems to break up the element, making it seem weightless.

Inside the excavated space, as in various works by Manrique, the dominant colour is white, in direct contrast with the volcanic stone of the exterior, establishing a relationship with the vernacular architecture of Lanzarote not in its form, but in the recognizable chiaroscuros present in the traditional domestic space. The unusual synthesis of these references, together with the awareness of contemporary art that had begun to develop in Madrid and New York, gives the project a clear singularity in the architectural parnorama of the time.

César Manrique's interest in the landscape of terraces is evident in his last major intervention in Lanzarote, the Jardín de Cactus [the Cactus Garden ] (1991) — a cactarium built in an old lapilli quarry or volcanic sand in Guatiza-, where he formed a kind of terraced amphitheater with plants, but it is in the Mirador del Río, carried out twenty years before, where the most interesting exchange and transfer of concepts, materials and construction systems takes place between the cultivation terrace and architecture. The result can be seen as an eclectic artistic synthesis of buried gardens and structures where organic forms with echoes of modernism are accommodated with the knowledge that a farmer and a geologist would have about the volcanic logic of the island, forming a new underground architectural landscape inside it (figure 10).

Through the section drawing it is possible to see this sequence of realities. The rational forms of the terraces, built with the living experience of the peasants are to the right. The center has the excavated space where various troglodytic references converge and on the left, the reality of the top of the mountain cut by a large window that makes a clear contrast with the stone where it touches the cliff. This project constitutes an organic complex that is difficult to classify, because it is a dialogue with both the memory of the infrastructures of the agricultural landscape and with the nature altered by the geophysical agents that characterize the island's geomorphology.

\section{THE MATERIAL ABSTRACTION OF AGRICULTURAL TERRACES IN BAIÃO, MOLEDO AND SANTA MARÍA DO BOURO BY EDUARDO SOUTO DE MOURA}

Souto de Moura is one of the architects who represents best the continuity of the exchanges between the terraces and architecture today. A small weekend refuge in Baião, Portugal, built between 1990-1993, is a clear example of p. 48 how residential architecture can inherit a great diversity of qualities from the previous agricultural landscape (figure 11). The arrangement and materiality of the pre-existing ruins on the plot, facing the Duero River as it passes through the Baião hills, anticípates, in some way, some of the transfers that would be carried out in the architectural project. A rural construction built with Portuguese granite ashlars seems to be related to the agricultural terraces of the hillside by aligning with them, also using the same material, thus remaining in physical and constructive contiguity with the farmland ${ }^{32}$. The removal of the ashlars from the retaining wall and the earthworks allowed the new house to be inserted, leaving the building in ruins as a walled yard or garden that served as a lobby.

There is a clear intention here to connect the memory of the old ruined rural house with the new building through the path followed by its inhabitants, who pass from a stone enclosure to a space built of concrete and camouflaged in the surroundings by a landscaped roof.

The new volume inserted by Souto de Moura, on a single level and without windows on all sides except for the front, directs its gaze towards the Duero river and the Cerdeira valley, adopting the orientation of the existing terraces. The glass plane reflects the surrounding landscape and the sky itself, using the ability of this material to, to some extent, disappear within its own reflection. Inside, a piece of masonry from the old terrace was reused to build the p. 49 chimney, serving as a material witness of the chosen transfer process. If the old ruined house, two stories high, looks like a vertical extension of the old terrace, the Portuguese architect's refuge prefers to consider it as an abstract fragment of an agricultural terrace, a topographic architecture capable of preserving, in some way, the natural freedom offered by the state of abandonment.

A house by the same architect, started in 1991 in the Portuguese town of Moledo de Minho, offers a similar response of integration in the terraced landscape, but this time selecting and discarding some of the transfers tested in the hills of Baião. In this small town in the municipality of Caminha, Souto de Moura found an area of agricultural terraces of approximately 1.5 meters, supported by stone retaining walls and overlooking the Atlantic Ocean. The program, somewhat larger than the one in the Baião refuge, is also organized perpendicular to a glass facade that aligns with the terraces. It was the original arrangement of these terraces, too close to each other to build the house, which forced a new strategy: the possibility of altering the topography with new walls and platforms (figure 12). This operation delayed the process for several years and ended up costing more than the house itself. In the words of Souto de Moura, the client, who, according to the Portuguese architect, was an intelligent man, "agreed, and over seven years the house gradually gained its independence, passing from being a redesign to a specific design for the occupants and the site which we progressively discovered and modified"33. 
p. 50 It is interesting to note the alteration of priorities for the project, capable of conceiving the terraced landscape as a fundamental part of the architecture of the house. Both the blind walls and the enclosure that flanks the wooden window were built with irregular dry blocks of granite, serving on the front as the exterior component of an insulating enclosure. The front elevation of the house allows it to be conceived as a vitreous cavity made in a granite terrace (figure 13), but the roof solution adopted was very different from that of Baião. The plant camouflage of the roof surface was not pursued here, in the author's own words: "The roof should be visible, assuming it's status as a new object which would be perceived as an object fallen from the sky" ${ }^{\prime 4}$. The slab, finished with a porous concrete pavement, was able to house the water collection system along with the overhead lighting and ventilation elements made of stainless steel in a less artificial way than in Baião. This is an operation of "literal" overlapping of domestic and agricultural architectures in the landscape of northern Portugal (figure 14).

This need to distinguish the roof, presenting it as reconfigured land, is consistent with the realization of a back door, a kind of patio open to the hillside that reveals the existence of a rock outcrop. This reinforces the presence of the material inside the house, forming two visual planes that seem to move towards and away from the interior at the same time: the Atlantic coast and the local stone ${ }^{35}$. This abstraction operation in the process of integrating the architecture on a remodeled terrace is reinforced by the reflections of both the landscape located in front of the house and the rock in the back.

Both house projects could be related to the experience of the Portuguese architect himself with contexts with a strong material imprint, such as the inn in Santa María do Bouro Monastery (1989-1997). The insertion of a part of the program at the base of the ruined building, forming a string course that extends horizontally, seems to dialogue with the terraces that descend down the slope and the materiality of the monastery itself. The way of approaching the notion of heritage adopted by this architect transcends the distinction between building and territory, since time is worked as a project material open to interpretation. In the case of the project for Santa María do Bouro, both the building and the nearby landscape could be considered as the raw material of a wider heritage that is in continuous construction. In the words of the Souto de Moura:

"Faced with two possible paths, we chose to reject the pure and simple consolidation of the ruin for the sake of contemplation, opting instead for the input of new materials, uses, forms and functions entre les choses, as Corbusier said. The 'picturesque' is a question of fate, not part of a Project or a program" 36 .

The end of the 20th century and the and the beginning of the 21 st century has been marked by a multiplication of transfers of the material and formal qualities of pre-existing agricultural structures and systems to rural and urban

p. 51 architecture, encouraged by a growing concern for issues related to landscape and the rising ecological awareness ${ }^{37}$. The surfaces of today's architecture are increasingly expanding the aspirations of continuity lost in modern architecture, offering the qualities of the ground and vegetation to mark the land or to regulate the temperature of buildings. This energy transfer seems to be accompanied by a constant conceptual, material and formal exchange that associates walls and terraces, downspouts and irrigation canals, roofs and cultivated soils, as had happened spontaneously in the excavated city of Matera, on the stone terraces of the Incas of Machu Picchu or on the irrigated terrace of the Generalife centuries ago. These examples are testimony to the logic of a transformation process that does not distinguish between disciplines, which dilutes the boundaries between landscape and architecture.

p. 52 The interest developed by contemporary architecture to integrate human works into the rural and natural environment, especially since the last decades of the twentieth century, seems to lead also to a certain admiration for the cohesive and adaptive capacity of traditional architecture. It aims to revive some of the conceptual and material borrowing that, spontaneously, helped to form architectural and landscape ensembles now declared as World Heritage sites. Although with very different critical outlooks, arising from organic thinking or from a rationality and material sincerity, César Manrique and Souto de Moura drew on the experience of the anonymous builders of the terraced landscape in rural environments and developed strategies capable of renewing the architecture of its time. The use of abstract and weightless glass panes, in contrast to the use of local materials such as stone and wood, aided by cement or reinforced concrete, allowed them to free the buried territory under the terrace from its natural darkness and open it towards the landscape that was in front of them. The care we perceive in the work of both architects towards the way in which materials age cannot be separated from their interest in work with time and memory, respect for pre-existing buildings and infrastructures as depositories of a material but also intangible heritage that, far from being paralyzed in time, can be renewed in each intervention.

\footnotetext{
1. Gianfranco Caniggia continued, in some way, the territorial perspective developed by his mentor Saverio Muratori, whose speculative discourse on the crisis of territory and architecture, begun in 1962, could find an answer in Civiltà and territory, encouraging a certain self-awareness of architectural work within a global balance of the territory. See MURATORI, S. Civiltà e territorio. Rome: Centro Studi di Storia Urbanistica, 1967.

2. CANIGGIA, Gianfranco; GIAN LUIGI, Maffei. Tipología de la edificación: estructura del espacio antrópico. Madrid: Celeste Ediciones, 1979, p. 24.

3. TRILLO DE LEYVA, Juan Luis. Argumentos sobre la contigüidad en arquitectura. Seville: Editorial Universidad de Sevilla, 2001, p. 132

4. ARCARAZ PUNTONET, Jon. La construcción del paisaje. Plan Parcial de Urbanización de Lanzarote. 1963. In: ZARCH: Journal of interdisciplinary studies in Architecture and Urbanism, 2016, n. ${ }^{7}$, p. p1. ISSN 2341-0531.

5. CASTELLANO PULIDO, Francisco Javier. El patrimonio fértil. Transferencias entre el paisaje agrario y la arquitectura en los crecimientos urbanos. Doctoral thesis. Universidad de Granada, 2015.
} 
6. TRILLO DE LEYYA, Juan Luis, op. cit. supra, nota 2, p. 132

7. TRILLO DE LEYVA, Juan Luis, op. cit. supra, nota 2, p. 21.

8. According to Trillo, this extrapolation to architecture can be pursued through the concept of fabulation. TRILLO DE LEYVA, Juan Luis, op. cit. supra, note 2, p. 76

9. DIXON HUNT, John. Greater perfections: the practice of garden theory. London: Thames \& Hudson, 2000, p. 85.

10. On the productivity of the platform system, see KAUFFMANN DOIG, Federico. Historia y arte del Perú antiguo. Lima: Ediciones Peisa-La República-Gloria, 2002.

11. HYSLOP, John. Inka settlement planning. Austin: University of Texas Press, 1990.

12. Susan A. Niles, in her study of agricultural works near Cusco (Cuzco), distinguished various types of platforms based on the construction techniques used -production, high prestige and mixed-or from their use -agricultural, experimental or scientific and for salt production. NILES, Susan A. Style and function in inca agricultural works near Cuzco. In: Ñawpa Pacha: Journal of Andean Archeology, 1982, No. 20, pp. 163-182. ISSN 0077-6297.

13. See MÚJICA, Elías. Andenes. Arquitectura productiva inca. In: Revista Arkinka. Lima: Arkinka, 1996, n. ${ }^{3}$, ISSN 1815-9273.

14. LAUREANO, Pietro. Atlas de agua: Ios conocimientos generales para combatir la desertificación. Barcelona: Laia, 2005, p. 156. English version: LAUREANO, Pietro. The water atlas: Traditional knowledge to combat desertification. Barcelona: Laia, 2012.

15. Ibíd., p. 204.

16. According to some authors, it seems likely that the terracing of the lands located below this ditch occurred after the creation of the Acequia Real [Royal irrigation canal] from the works of the founder of the Nasrid dynasty Muhammad I (1238-1272). TITO ROJO, José; CASARES PORCEL, Manuel. El jardín hispanomusulmán: los jardines de al-Andalus y su herencia. Granada: Universidad de Granada, 2011, p. 228.

17. See ORIHUELA UZAL, Antonio; RODRÍGUEZ MORENO, Miguel. Casas y palacios nazaries: siglos XII-XV. Sevilla: Junta de Andalucía, Consejería de Cultura, Consejería de Turismo y Deporte; Granada: El Legado Andalusí; Barcelona: Lunwerg Editores, 1996. See also VíLCHEZ VíLCHEZ, Carlos. El Generalife. Granada: Proyecto Sur, 1991, p. 31.

18. The pond of the Patio de la Sultana, previously named Estanque de los Peces, was part of the hydro-agricultural system and was, by its location, the oldest on the site, probably predating the Albercón de las Damas. TITO ROJO, José; CASARES PORCEL, Manuel, op. cit. supra, note 15, p. 394.

19. Ídem.

20. Spain has conserved numerous testimonies of property and ethnological heritage, built with the same logic that the terraces are built, in contiguity with them, as can be seen in the use of dry stone in Catalonia and Aragon, in the rural area of Sierra Mágina, in Jaén, in the Sierra de Enguera, Valencia, or in Menorca. Without mortar or binder, it is a technique that is part of a subsistence economy that takes advantage of the proximity of local resources, such as the reuse of the stones cleared from crop fields or turf that accumulate in the margins. Hormas, chozos, eras and casetas, some from the 18th century, are usually auxiliary spaces for shepherds and also form part of terraces and land delimitation elements. ESCOBEDO MOLINOS, Enrique. Los chozos de piedra. En: Jaén, pueblos y ciudades. Jaén: Diario Jaén, 1997-2000, p. 2095.

21. DIXON HUNT, John, op. cit. supra, nota 8, p. 85.

22. One precedent of this sensitivity towards the terraces as a heritage to be recovered within the city is found in The civic Survey of Edinburgh, by Patrick Geddes. See CASTELLANO PULIDO, Francisco Javier. Infrastructure and memory: from the agricultural terraces of Geddes to the overlapping landscapes of Beigel. In: Proyecto, Progreso, Arquitectura. Arquitectura e infraestructura. Seville: Editorial Universidad de Sevilla, November 2015, n. ${ }^{\circ}$ 15, pp. 74-89. ISSN 2171-6897.

23. See the example of the Rumeu house, built entirely with Cadaqués stone, as used to make the retaining wall of the Julià house. These native stone walls, less expensive than brick structures, established, despite the hexagonal geometry of the house, a landscape motif linked to the rural context, using the same stone as in the terraces outside. Inside, the furniture was designed to take advantage of the uneven floor, transferring the same logic from the existing agricultural terraces. LLOBET RIBEIRO, Xavier. Casa Rumeu. In: Docomomo Ibérico. Documentation and Conservation of the Architecture and Urbanism of the Modern Movement [online]. Fundación Docomomo Ibérico [retrieved: 16-12-2018]. Available in: http://www.docomomoiberico.com/. See the publisehd project in CORREA, Federico; MILA, Alfonso. Casa Rumeu. In: Cuadernos de Arquitectura. Viviendas unifamiliares. Barcelona: Colegio Oficial de Arquitectos de Catalunya y Baleares, 2. trimester 1964, n. ${ }^{\circ}$ 56, pp. 15-17. ISSN 0011-2364.

24. MANRIQUE, César, et al. Lanzarote, arquitectura inédita: geología y paisaje, vivienda popular, arquitectura religiosa, arquitectura militar, chimeneas, puertas y ventanas, molinos. Arrecife, Lanzarote: Cabildo Insular, Servicio de Publicaciones, 1988. Original edition: 1974.

25. DíAZ HERNÁNDEZ, Ramón; DOMÍNGUEZ MÚJICA, Josefina; PARREÑo CASTELLANO, Juan Manuel. La utopía de Manrique: el paisaje reinventado y la apropiación turística. In: Nuria BENACH, Miriam Hermi ZAAR, Magno VASCONCELOS P. JUNIOR, eds. Conference Proceedings XIV Coloquio Internacional de Geocrítica. Las utopías y la construcción de la sociedad del futuro. Barcelona, 2-7 de mayo de 2016 [online]. Barcelona: Universidad de Barcelona, 2016 [retrieved: 10-01-2019]. ISBN 978-84617-5447-2. Available in: http://www.ub.edu/geocrit/xiv_diazdominguez.pdf

26. Manrique went to the exhibition "Architecture without architects", organized in 1964 at the Museum of Modern Art in New York. It featured the landscape of La Geria in Lanzarote, decisively influencing his subsequent decisions. SABATÉ, Fernando; SABATÉ, Joaquín; ZAMORA, Antonio. César Manrique: la conciencia del paisaje. In: Joaquim SABATÉ, José FARRUJIA, coords. César Manrique: la conciencia del paisaje. Santa Cruz de Tenerife: Fundación Cajacanarias, 2013, p. 31.

27. The series of projects that he developed after the trip made in 1963 are of special interest. He travelled with his friend, the architect Fernando Higueras, who is another of the references for the appropriation of the construction strategies from the agricultural landscape of Lanzarote as a reference of its architecture. ARCARAZ PUNTONET, Jon, op. cit. supra, nota 3, p. 91.

28. DíAZ HERNÁNDEZ, Ramón et al., op. cit. supra, nota 24.

29. As Francisco Galante describes, in the stratified walls "it was necessary to install wooden beams with sufficient inclination to place on them a dry stone wall supported by a light layer of concrete (...), the monumental doorway, on the contrary, was made with large pieces of stone, conveniently numbered after collection for final installation". GALANTE, Francisco; ALBORNOZ, Pedro. Mirador del Río. Teguise, Lanzarote: Fundación César Manrique, 2000, p. 55.

30. Ídem. On this type of constructions, often integrated with the terraces, similar to the huts of Sierra Mágina, see also FARRAY BARRETO, J:; MONTELONGO FRÁNQUIZ, A. J. Refugios agrícolas, torres de vigilancia y taros en Lanzarote. In: X Jornadas de Estudios sobre Lanzarote y Fuerteventura. Arrecife (Lanzarote): Servicio de Publicaciones de los Excmos. Cabildos Insulares de Lanzarote y Fuerteventura, 2004, p. 93

31. These are caves formed by lava bubbles, some of which were transformed by César Manrique in the 1960s, anticipating issues raised by land art. See MADERUELO, Javier. Jameos del Ağua. Lanzarote: César Manrique Foundation, 2006.

32. BROTO, Carles; MINGUET; Josep Maria. Houses. Sant Adrià de Besòs: Instituto Monsa de Ediciones, 1996.

33. SOUTO DE MOURA, Eduardo. Casa en Moledo. In: EI Croquis, 2005, n. ${ }^{\circ} 124$, p. 54. ISSN 0212-5633.

34. Ídem.

35. SCHITTICH, Christian; RÜDIGER Krisch. In Detail: Single Family Houses. Basilea-Boston-Berlín: Birkhäuser, 2005, p. 148.

36. SOUTO DE MOURA, Eduardo. Rehabilitación para Pousada del Monasterio Cisterciense de Santa María do Bouro. In: El Croquis, 2005, n. ${ }^{\circ}$ 124, p. 28.

37. See, for example, OAB+ADI Arquitectura. Construir sin destruir, casa BF. In: TC Cuadernos [online]. Valencia: General de Ediciones de Arquitectura, December 2016 [retrieved: 10-01-2019]. Available in: https://www.tccuadernos.com/blog/construir-sin-destruir-casa-bf/. See also SCHULZ-DORNBURG, Julia. Casa Bancal. In: HIC arquitectura March 2013 [online] [retrieved: 10-01-2019]. Available in: http://hicarquitectura.com/2013/03/julia-schulz-dornburg-casa-bancal/ 


\section{Autor imagen y fuente bibliográfica de procedencia}

Información facilitada por los autores de los artículos:

página 14, 1 (Fotos del Museo Etnográfico de Garachico); páginas 15 a 18, 2 a 7 (Juan Manuel Palerm Salazar); página 23, 1 (BONSALL, Clive; RADOVANOVIĆ, Ivana; ROKSANDIĆ, Mirjana; COOK, Gordon; HIGHAM, Thomas; PICKARD, Catriona. Dating burial practices and architecture at Lepenski Vir. In: Clive BONSALL, Ivana RADOVANOVIĆ, Vasile BORONEAN, eds, The Iron Gates in Prehistory: new perspectives. Oxford: Archaeopress, 2008, BAR International Series, vol. 1893, pp. 175-204 (based on a drawing by Dušan BORIĆ)); página 24, 2 (Nemezis, own work, CC BY-SA 3.0); página 25, 3 (SREJOVIĆ, Dragoslav. Lepenski Vir: Nova praistorijska kultura u Podunavlju. Belgrade: Srpska književna zadruga, 1969); página 26, 4 (Lucija Ažman Momirski); página 27, 5 (van ESS, Margarete; NEEF, Reinder. Rohstoff Schilf. In: Nicola CRÜSEMANN, Margarete van ESS, Markus HILGERT, Beate SALE, Uruk-5000 Jahre Megacity. Curt-Engelhorn-Stiftung, Deutschen Archäologischen Institut, Deutschen Orient-Gesellschaft e. V., Vorderasiatischen Museum, Reiss-Engelhorn-Museen Mannheim, Staatliche Museen zu Berlin, 2013, pp. 114-115); página 28, 6 (Lucija Ažman Momirski); página 30, 7 (Lucija Ažman Momirski); página 29, 8 (Lucija Ažman Momirsk); página 30, 9 (Google Earth); página 31, 10 (Matevž Lenarčič); página 31, 11 (Lucija Ažman Momirski); página 31, 12. (Lucija Ažman Momirski). página 38, 1 (Francisco Javier Castellano Pulido); página 39, 2-3 (Fotografía: Hiram Bingham, 1912. Original en revista Mensual Harpers, 1912. Fuente: National Geographic. Disponible en: https://www.nationalgeographic.com/magazine/1913/04/machu-picchu-peru-inca-hiram-bingham-discovery/); página 39, 4 (Elaboración propia a partir de esquema en LAUREANO, Pietro. Atlas de agua: los conocimientos generales para combatir la desertificación. Barcelona: Laia, 2005);

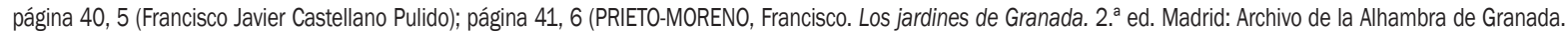
Patronato de la Alhambra y Generalife, 1973); página 42, 7 (Elaboración propia. La fase B modifica la hipótesis de la alberca del patio del Ciprés de La Sultana de C. Vîlchez sobre dibujo de R. Cabrera Orti en VíLCHEZ VíLCHEZ, Carlos. El Generalife. Granada: Proyecto Sur, 1991, p. 31.); página 44 y 45, 8-9 (Fotografías: Pedro Albornoz. Cortesía de la Fundación César Manrique); página 46, 10 (Cortesía de los Centros de Arte, Cultura y Turismo de Lanzarote); página 46, 11. (Fotografía: Luís Ferreira Alves); página 47, 12 (Elaboración propia a partir de planimetría actualizada cortesía de Eduardo Souto de Moura); página 48, 13 (Fotografía: Luís Ferreira Alves); página 49, 14 (Elaboración propia a partir de planimetría actualizada cortesía de Eduardo Souto de Moura); página 50, 15 (Cortesía del fotógrafo Luís Ferreira Alves); página 54, 1, página 58, 2, página 59, 3, página 60,4, página 61, 5, página 62, 6, página 63, 7 y 8, página 65, 9, página 66, 10, página 67, 11, página 68, 12 y 13, página 69, 14 (Susana López Varela); página 74, 1 (Sonia Delgado Berrocal); página 742 (Elaboración propia con la herramienta Visor GeoSINIA, en https://sinia.minam.gob.pe); página 75, 3 y 4, página 76, 5 y 6 (Sonia Delgado Berrocal); página 77, 7. (Elaboración propia a partir de información del Ministerio de Cultura de Perú); página 78, 8 y 9 (Sonia Delgado Berrocal); página 80, 10, página 81, 11 (Sonia Delgado Berrocal); página 82, 12 (Elaboración propia a partir de datos recogidos en SENAMHI, 2009. http://catalogo.geoidep.gob.pe:8080/ metadatos/srv/api/records/3e9c4e25-52ba-4475-ac09-f09a366e287c); páginas 88 a 96, 1 a 12 (๔ Beatrice Agulli); página 102, 1 (Avalon Distribución Audiovisual S. L); página 104, 2 (Avalon Distribución Audiovisual S. L.); página 104, 3 (Sigurd Morken); página 106, 4 (Avalon Distribución Audiovisual S. L.); página 107, 5 y 6 (Pablo López Santana); página 108, 7 (Avalon Distribución Audiovisual S. L.); página 108, 8 (Izquierda: BMG Music Spain, S. A.; derecha: Museo de Arte Turco e Islámico de Estambul); página 109, 9 (Avalon Distribución Audiovisual S. L.); páginas 115 a 128, 1 y 12 (José María Jové Sandoval); página 127, 13 (Fotografía: Taliesin West Pergola. Wisconsin Historical Society. WHi-144493); página 129, 14 (José María Jové Sandoval); página 130, 15 (Fotografía: Taliesin West. Wisconsin Historical Society. WHi-144492); página 137, 1. (Fotografía: Désiré Charnay.The Miriam and Ira D. Wallach Division of Art, Prints and Photographs: Photography Collection, The New York Public Library. “Vue General Des Ruines, à Uxmal". New York Public Library Digital Collections. [acceso: 06-07-2019]. http://digitalcollections.nypl.org/items/510d47db-11f9-a3d9-e040-e00a18064a99 y Planta de Uxmal. Rare Book Division, The New York Public Library. “Plan of Uxmal” New York Public Library Digital Collections. Accessed July 6, 2019. http://digitalcollections. nypl.org/items/510d47db-1210-a3d9-e040-e00a18064a99); página 137, 2 (Archivo Henri Stierlin); página 138, 3 (Planos Coop.6 - S.393 y Coop.4 - S.391. Fundación Rogelio Salmona); página 139, 4 (Plano S. N. y redibujo Fundación Rogelio Salmona); página 140, 5 (Plano ALP.26 - S.1690. Fundación Rogelio Salmona. Plano de localización Clara Mejía Vallejo y Ricardo Merí de la Maza); página 141, 6 (Plano Coop.2 - S.389 y otros redibujos. Fundación Rogelio Salmona); página 142, 7 (Fundación Cristina de la Vivienda. Fotografía de conjunto. Fundación Rogelio Salmona. Plano de localización Clara Mejía Vallejo y Ricardo Merí de la Maza); página 143, 8 (Planos CAV.1 - S.566 y FCV 6. S 581. Fundación Rogelio Salmona); página 144, 9 (Boceto JAE 023-036-136. Fundación Rogelio Salmona y fotografía exterior @Leonardo Finotti); página 146, 10 (Plano UP.006 -02B-099 y fotografía de maqueta. Fundación Rogelio Salmona); página 147, 11 (Fotografías de maqueta. Fundación Rogelio Salmona); página 148, 12 (Plano CC/ Z028-07A-289. Fundación Rogelio Salmona); página 149, 13 (Estudios previos julio 23/80 CCB 149-05A-266, julio 23/80 CCB 150-05A, febrero 6/80 CCB 126-05A-266, enero 31/80 CCB 123-05A-266, diciembre 19/79 CCB 019-05A-264. Fundación Rogelio Salmona); página 150, 14 (Fotografías exteriores: rampa de acceso a la cubierta. (c) Leonardo Finotti y fotografía patio del caucho ( E Enrique Guzmán); página 150, 15 (Fotografía: Désiré Charnay. The Miriam and Ira D. Wallach Division of Art, Prints and Photographs: Photography Collection, The New York Public Library. "Ancien Temple, à Chichen-Itza, applé le chateau". New York Public Library Digital Collections. [acceso: 0607-2019]. http://digitalcollections.nypl.org/items/510d47db-11e9-a3d9-e040-e00a18064a99 y Casa de los Huéspedes de Colombia fotografía del exterior (estado actual) (c) Leonardo Finotti); 
Y SOUTO DE MOURA / LIVING TERRACES: FROM REUSE IN TRADITIONAL ARCHITECTURE TO CÉSAR MANRIQUE AND SOUTO DE MOURA'S WORK WITH TIME. Francisco Javier Castellano Pulido • ESTRATEGIAS TERRITORIALES INTEGRALES PARA LA PUESTA EN VALOR DE PAISAJE CULTURAL AGRÍCOLA. LA RIBEIRA SACRA, GALICIA, ESPAÑA/COMPREHENSIVE TERRITORIAL STRATEGIES TO ENHANCE THE AGRICULTURAL-CULTURAL LANDSCAPE. RIBEIRA SACRA, GALICIA, SPAIN. Susana lópez Varela • PAISAJES DE ALTURA: lOS ANDENES DEL DISTRITO DE CABANA, VALLE DEL SONDONDO, PERÚ / HIGH LANDSCAPES: THE ANDENES OF THE DISTRIT OF CABANA, SONDONDO VALLEY, PERU. SOnia Delgado Berrocal • COLTIVARE I TERRAZZAMENTI AI PIEDI DEL MONTE BIANCO. LA "VITICOLTURA EROICA" DI MORGEX / CULTIVATING THE TERRACES AT THE FOOT OF MONT BLANC. THE "HEROIC VITICULTURE" OF MORGEX. Beatrice Agulli - SIAH DAREH. TERRAZAS Y PAISAJE EN ABBAS KIAROSTAMI / SIAH DAREH. TERRACES AND LANDSCAPE IN ABBAS KIAROSTAMI. Pablo López Santana • FRANK LLOYD WRIGHT. TRABAJAR LA TIERRA PARA UN PAISAJE SIMBIÓTICO / FRANK LLOYD WRIGHT. EARTHWORK FOR A SYMBIOTIC LANDSCAPE. José María Jové Sandoval • ROGELIO SALMONA Y LA CONSTRUCCIÓN DEL LÍMITE. DIÁlOgOS ENTRE TOPOGRAFÍA Y PAISAJE / ROGELIO SALMONA AND THE CONSTRUCTION OF LIMITS. DIALOGUES BETWEEN TOPOGRAPHY AND LANDSCAPE. Clara Mejía Vallejo; Ricardo Merí de la Maza • RESEÑAS BIBLIOgRÁFICAS • RODRIGO ALMONACID CANSECO: EL PAISAJE CODIFICADO EN LA ARQUITECTURA DE ARNE JACOBSEN . Carlos Santamarina-Macho • JAVIER MADERUELO: EL PAISAJE. GÉNESIS DE UN CONCEPTO. Victoriano Sainz Gutiérrez • GEORG SIMMEL: FILOSOFÍA DEL PAISA JE. Esther Mayoral Campa.

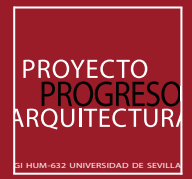
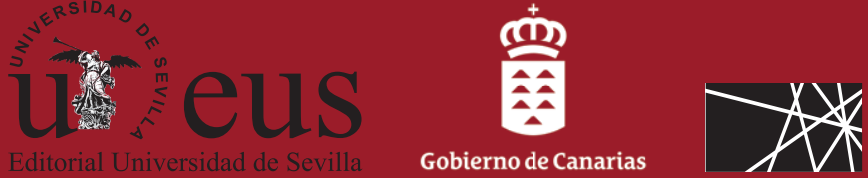